\title{
Hacia un balance de la historiografía regional santandereana (Colombia): los municipios del área del río Sogamoso (1930-2017)*
}

\section{Resumen}

Este artículo es un aportar a la elaboración de un balance general de la historiografía regional en Santander, Colombia. La búsqueda fue exhaustiva, pero priorizando los municipios ubicados en la cuenca del Río Sogamoso (Barrancabermeja, Puerto Wilches, Sabana de Torres, Lebrija, Girón, Los Santos, Zapatoca, Betulia y San Vicente de Chucurí). Se usó una metodología que incluyó el diseño de un instrumento de captura de información y una búsqueda sistemática en las principales bibliotecas y bases de datos. Entre las conclusiones, se evidencia la abundancia de investigaciones en el siglo XIX. Además, las universidades públicas han cumplido su rol sobre la región en materia de aportes históricos-investigativos con temas como: problemáticas de colonización y poblamiento del territorio, la guerra y la violencia, los movimientos sociales, entre otros. Las cuestiones políticas, geográficas, ambientales, educativas y religiosas ocupan un lugar secundario y marginal en las investigaciones. No obstante, dicha bibliografía se encuentra insuficientemente divulgada, de manera que el conocimiento histórico construido no ha incidido mucho en la sociedad del departamento y la región.

\section{Palabras clave}

Tesauro: historiografía.

Autor: Santander (Colombia), Río Sogamoso (Colombia), regiones.

Referencia bibliográfica para citar este artículo: Plata Quezada, Wilmer Elvis. "Hacia un balance de la historiografía regional santandereana (Colombia): los municipios del área del río Sogamoso (1930-2017)". Anuario de Historia Regional y de las Fronteras, 25.1 (2020): 223 - 265

Fecha de recepción: 19/01/2019

Fecha de aceptación: 06/06/2019

William Elvis Plata Quezada: Doctor en Historia por la Facultés Universitaires Notre Dame de la Paix. Director del grupo de investigación sobre el hecho religioso: "Sagrado y Profano". Profesor asociado de la Universidad Industrial de Santander, UIS. Código ORCID: 0000-0001-6164-1037. I.D. SCOPUS: 57188732206. Correo electrónico:weplataq@uis.edu.co

\footnotetext{
*Artículo es fruto del proyecto de investigación: "Construcción de la memoria histórica en la región del Río Sogamoso", financiado por ISAGEN y el Programa de Desarrollo y Paz del Magdalena Medio.
} 


\title{
Towards a balance of the regional historiography of Santander (Colombia): the municipalities of the Sogamoso River area (1930-2017)
}

\begin{abstract}
This article is a contribution to the elaboration of a general balance of regional historiography in Santander, Colombia. The search was exhaustive, but prioritizing the municipalities located in the Sogamoso River basin (Barrancabermeja, Puerto Wilches, Sabana de Torres, Lebrija, Girón, Los Santos, Zapatoca, Betulia and San Vicente de Chucurí). It was used a methodology which included the design of an information capture instrument and a systematic search in the main libraries and databases. Amongst the conclusions, the abundance of research in the nineteenth century is evident. Additionally, public universities have fulfilled their role in the region regarding historical-research contributions with issues such as: problems of colonization and population of the territory, war and violence, social movements, amongst others. Political, geographical, environmental, educational and religious issues occupy a secondary and marginal place in research. However, this bibliography is insufficiently disseminated in a way that the historical knowledge built has not greatly affected the society of the department and the region.
\end{abstract}

Keywords

Tesauro: historiography.

\section{Rumo a um balanço da historiografia regional de Santander (Colômbia): os municípios da região do rio Sogamoso (1930-2017)}

\section{Resumo}

Este artigo é uma contribuição para a elaboração de um balanço geral da historiografia regional em Santander, Colômbia. A busca foi exaustiva, mas priorizou os municípios localizados na bacia do rio Sogamoso (Barrancabermeja, Puerto Wilches, Sabana de Torres, Lebrija, Girón, Los Santos, Zapatoca, Betulia e San Vicente de Chucurí). Foi utilizada uma metodologia que incluiu o desenho de um instrumento de captura de informações e uma busca sistemática nas principais bibliotecas e bancos de dados. Entre as conclusões, a abundância de pesquisas no século XIX é evidente. Além disso, as universidades públicas cumpriram seu papel na região em questões de contribuições da pesquisa histórica com questões como: problemas de colonização e população do território, guerra e violência, movimentos sociais, entre outros. Questões políticas, geográficas, ambientais, educacionais e religiosas ocupam um lugar secundário e marginal na pesquisa. No entanto, esta bibliografia é insuficientemente disseminada, de modo que o conhecimento histórico construído não afetou muito a sociedade do departamento e da região.

Palavras chave

Tesauro: historiografia. 


\section{Introducción}

Son prácticamente inexistentes los balances publicados sobre la historiografía regional del actual departamento de Santander, de manera que el presente documento ayudará a los historiadores e investigadores regionales en sus procesos de localización y fundamentación bibliográfica.

Este artículo expone resultados de la primera parte de un proyecto de revisión de la historiografía sobre el departamento de Santander, Colombia. En este caso, nos hemos centrado en los municipios de la zona aledaña al Río Sogamoso: Barrancabermeja, San Vicente de Chucurí, Betulia, Zapatoca, Los Santos, Girón, Lebrija, Sabana de Torres y Puerto Wilches. El Río Sogamoso nace de la confluencia de los ríos Suárez y Chicamocha y desemboca en el río Magdalena. Conforma una zona que integra la región andina con el Magdalena Medio, el Santander andino, tradicional, con el Santander rivereño, más "nuevo" y diverso. Es además, una zona en transformación por las fluctuaciones de la economía petrolera, cacaotera y más recientemente, por la construcción de la represa de Hidrosogamoso, que está afectando a nueve importantes municipios, en los cuales, precisamente, se centra este trabajo. Conscientes de que la construcción de tal represa significa una coyuntura histórica para la mayoría de estos municipios y para esta subregión, por todas las consecuencias geográficas, económicas, sociales y culturales que implica, pensamos en la necesidad de elaborar a futuro una historia de larga duración de esta zona. El presente balance, significa, entonces, un punto de partida en dicho proyecto. Además, sirve como test aproximativo del estado de la historiografía regional de Santander.

Cierto es que varios de los municipios no pertenecen exclusivamente a esta subregión y que sus historias están circunscrita además a otras provincias o zonas. Es, por ejemplo, el caso de Girón, que es un territorio con jurisdicción en la región del Sogamoso, pero también en la región del Lebrija o el Magdalena y la provincia andina de Soto, por lo que los autores y las temáticas mencionadas no se centran específicamente en la región del Sogamoso. No obstante, hemos querido abordar, en la medida de lo posible, la totalidad de los textos históricos sobre cada uno de los municipios del área, conscientes de la importancia de dar u primer paso en la construcción de una historiografía general de Santander.

Este balance pretende ser exhaustivo, es decir, abarcar la gran mayoría de las publicaciones existentes sobre la historia y memoria de dichas poblaciones. Para conseguir este objetivo se utilizó una metodología que incluyó el diseño de un instrumento de captura de información (base de datos) y una búsqueda sistemática en las principales bibliotecas y bases de datos depositarias de la información requerida. Se aprovechó la existencia de reseñas y resúmenes, como de ediciones digitales de buen parte de dicha bibliografía. Un grupo significativo la constituyen tesis de grado, a buena hora digitalizadas por las bibliotecas universitarias que las contienen, lo cual 
facilitó el acceso a la información. En total se registraron y ficharon 185 publicaciones, entre libros, artículos y capítulos de libro. Para una mejor presentación, hemos preferido listar las obras al final, organizadas por temas y subtemas, limitándonos a referenciarlas a pie de página solo en ciertos casos.

A pesar de que el estudio se hace sobre una "muestra" de los municipios del departamento de Santander, buena parte de los resultados expuestos pueden extrapolarse, tanto al departamento, como a la región del noroccidente colombiano, pues, consideramos, abordan elementos comunes.

\title{
2. Los estudios históricos regionales en Santander
}

La historia regional surge del trabajo realizado por la Escuela de los Annales en Francia, y por la llamada "microhistoria" mexicana, aunque no se equipara a esta. Busca profundizar en el ámbito local y regional, bien para poner a prueba la validez de hipótesis e interpretaciones hechas sobre la historia nacional o bien para estudiar en detalle la cultura e identidad locales y definir sus particularidades. Fue además un llamado de atención de las regiones a las estructuras centrales de sus países, sobre las diferencias y particularidades de la experiencia regional en relación a los centros referenciales.

En Colombia esta tendencia está muy ligada al surgimiento y desarrollo de los estudios profesionales en Historia y ciencias sociales en distintos departamentos, lo cual se verificó a partir de la década de 1970, ${ }^{1}$ especialmente en Antioquia y el Valle, regiones con cierto sentido identitario ligado a "mitos" fundacionales (como la colonización Antioqueña y la cultura del café o la supuesta "integración" de las "razas" en torno a la economía de la Caña de azúcar) que era necesario revisar y estudiar a profundidad. Entre los pioneros de la historiografía regional en Colombia se encuentran Germán Colmenares y Orlando Fals Borda. Así, de acuerdo con Ramírez Bacca,

\begin{abstract}
La mencionada profesionalización de la disciplina en las universidades públicas y privadas de provincia permitió un boom de los estudios regionales desde los años ochenta. En un país donde es evidente la carencia de recursos para la investigación, la historia regional y local se convierte en un modo práctico de incursionar en la disciplina. De una parte, se ve acompañada de un proceso de sistematización de archivos locales y regionales; de otra, por enfoques locales, subregionales y regionales, que se convirtieron en una alternativa historiográfica frente a la tradición de las historias patrias e historias nacionales; y finalmente, por la limitada ausencia de discusiones teóricas y la problematización del concepto Región [...]. ${ }^{2}$
\end{abstract}

\footnotetext{
${ }^{1}$ Si bien el primer programa profesional en historia nació en Bogotá, en 1964, fue en las regiones donde más rápidamente se desarrollaron estos estudios.

2 Enzo Ramírez Bacca, «Tendencias de la historia regional en Colombia. Problemas y perspectivas recientes» En Historelo. Revista de Historia Regional y Local. 3.5 (2011):152.
} 
Aunque ya desde los años 1920 se venían cultivando por las élites locales santandereanas un cierto tipo de historia local y regional, limitada al estudio de personajes, acontecimientos y "héroes" locales, ${ }^{3}$ los estudios profesionales de historia regional en el departamento solo inician a partir de los años 80, con la fundación de la Escuela de Historia de la Universidad Industrial de Santander (UIS). Y todo esto, gracias a un accidente: el incendio de un archivo histórico judicial en la ciudad de Girón, en 1983, que obligó a las autoridades a buscar una institución que rescatara y protegiera la documentación sobreviviente. La UIS tomó el proyecto e inició un proceso que tuvo su cénit en la creación de la Carrera de historia en 1987. Esto, a pesar de un ambiente poco propicio para el desarrollo de este tipo de temas en una sociedad marcada por el pragmatismo, el individualismo y la búsqueda del éxito económico. ${ }^{4}$

Para apoyar este proceso, en 1988 se creó el Centro de Documentación e Investigación Histórica Regional y se inició un proyecto de investigación sobre de la subregionalización de Santander, que incluía la definición histórica de términos y el estudio de los orígenes de los distintos municipios del departamento. ${ }^{5}$

Desde entonces, la UIS ha sido la entidad que ha liderado los estudios históricos regionales en el nororiente colombiano; ello, a pesar de que varios profesores que iniciaron con entusiasmo a trabajar en esta línea, pronto fueron cambiando sus intereses, urgidos, según afirma Armando Martínez, por parecer menos "parroquianos" ante sus colegas del centro del país. Quizá en el fondo, nunca se creyó en esa línea de trabajo. De acuerdo con Martínez, se escucharon los llamados que hiciera Jorge Orlando Melo a fines de los años 90, en torno a recuperar la historia política, que había sido supuestamente abandonada por la Nueva Historia, en su reacción contra la historia tradicional que producían las academias de historia. ${ }^{6}$ Así, se dejó a un lado la historia regional por la historia del Estado - nación, con un enfoque institucional - administrativo, de "arriba hacia abajo" y privilegiando el siglo XIX y comienzos del XX. En palabras de Martínez: "[...] Diez años dedicados a la historia regional santandereana nos trajo la crítica que éramos localistas y parroquianos. Entonces me puse a pensar como trabajar una historia de la nación y no de la región".?

\footnotetext{
3 Gabriel Samacá, Historiógrafos del solar nativo. El centro de historia de Santander 1929 - 1946. (Bucaramanga, UIS, 2015).

4 Álvaro Acevedo Tarazona, (Comp.), Relatos de la Escuela. Orígenes del programa de Historia. (Bucaramanga, UIS, 2013): 53.

${ }^{5}$ La investigación dio como fruto, entre otros, cinco libros dedicados a cada una de las provincias de Santander, Una obra compuesta por artículos miscelánicos sobre la historia regional de Santander y varios informes inéditos.

${ }^{6}$ María Fernanda Duque Castro, “¡Para mí, sin archivo no hay historia! Entrevista con el historiador Armando Martínez Garnica”. En Academia.edu. Consultado en julio de 2013. [en línea] http://www. academia.edu/393720/_Para_mi_sin_archivo_no_hay_Historia_.Entrevista_con_el_profesor_Armando_ Martinez_Garnica_-_Historiador.

${ }^{7}$ Duque, 3
} 
Así, ante la falta de procesos sistemáticos, de guías y agendas de trabajo, la historia regional de Santander ha estado desarrollada de forma atomizada y han sido, en buena parte, los estudiantes y egresados del programa de historia de la UIS quienes se han encargado fundamentalmente de historiar la región, labor siempre sujeta a las "modas" intelectuales del momento. De manera que, desde los años 8090 , no ha vuelto a haber un gran proyecto que intente comprender las dinámicas de funcionamiento histórico de las regiones y subregiones del nororiente colombiano. Eso no significa que haya pocos trabajos; por el contrario, únicamente para la subregión del Río Sogamoso, se han contabilizado casi 190 producciones, sin tener en cuenta las otras provincias y zonas del departamento. Infortunadamente, muchas de estas investigaciones se quedan en las bibliotecas como trabajos de grado y no llegan al gran público, desaprovechando el enorme esfuerzo investigativo realizado.

Por otra parte, se trata de investigaciones que disponen de abundante material empírico, pero son, generalmente, poco analíticas; no realizan mayores esfuerzos interpretativos, o para poner en duda hipótesis generalizadoras hechas desde el centro; hay así, mucha información esperando ser analizada. Tampoco se discute la relación entre el espacio y la región. (dominio del espacio y su apropiación como fundamento de construcción de región); es decir, se ha trabajado la región sin tener clara una conceptualización de la misma. Finalmente, y esto sorprende un poco, no se ha aceptado la invitación de Luis González González de hacer una historia "total" local y regional, la conocida "microhistoria" mexicana, muy útil para la realidad de nuestro país y de los pueblos que lo componen. ${ }^{8}$

Está así, en mora, la realización de una gran obra que sintetice y divulgue la producción de más de 30 años, y que permita comprender mejor la historia santandereana y superar muchos mitos sin fundamentos que aún se propagan como verdades históricas.

\section{Análisis externo de la bibliografía}

\subsection{Una región cada vez más interesante para los investigadores}

Más del 86\% de las obras han sido publicadas posterior a 1980, y el 55\% después de 2001. Eso quiere decir que en las últimas décadas se ha experimentado una auténtica "explosión" investigativa sobre la región, la cual apenas se estudiaba antes de 1980. Las razones de tal dinamismo son varias; una de ellas ha sido el desarrollo de los estudios universitarios en el departamento, con la creación, a partir de esa década, de programas en historia, ciencias humanas y sociales que han motivado a los estudiantes a investigar sobre la región. Otro factor ha sido el mayor apoyo relativo que ha venido teniendo la investigación, especialmente en universidades e instituciones

\footnotetext{
${ }^{8}$ Luis González, Pueblo en Vilo. Microhistoria de San José de Gracia. $3^{\mathrm{a}}$ ed. (México, El Colegio de México, 1979); Luis González, Invitación a la microhistoria. (México, Fondo de Cultura Económica, 1986): 147; Luis González, Otra invitación a la microhistoria. (México, Fondo de cultura Económica, 2011): 87.
} 
culturales y sociales. Además, las problemáticas ligadas a los movimientos sociales característicos en la región y al conflicto armado que ha azotado a sus poblaciones ha llamado la atención de los investigadores, no solo del departamento, sino también de otras zonas del país y aún del extranjero.

Gráfico No. 1

Año de Publicación

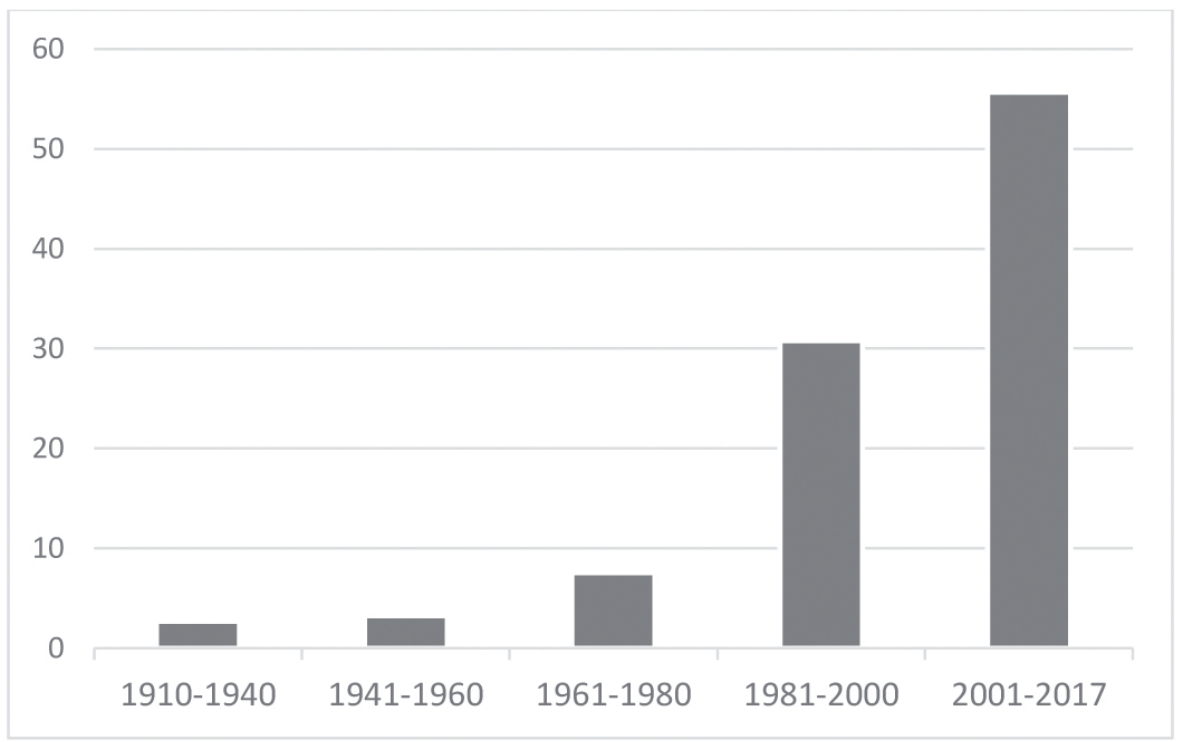

Fuente: elaboración propia a partir de bases de datos bibliográficas

\subsection{La universidad pública: promotora de una investigación histórica que no ha trascendido}

La gran mayoría de las obras $(56 \%)$ han sido editadas y/o producidas por instituciones universitarias, destacándose, en este grupo la Universidad Industrial de Santander como gestora y editora de publicaciones sobre historia y memoria de la región y del departamento. En un reducido 17\% las obras han sido editadas por entidades públicas no educativas (alcaldías, gobernaciones, etc.); el 14\% siguiente por editoriales locales o nacionales y seguidamente (11\%) las organizaciones sociales, culturales y otras entidades. La Universidad pública, entonces, ha estado cumpliendo su papel de vincularse estrechamente a la región en cuanto promotora de investigaciones sobre la realidad, en este, caso, de tipo histórico y preocupada por conocer las lógicas de poblamiento, económicas, políticas y de conflicto social, que han caracterizado a esta zona. 
Hacia un balance de la historiografía regional santandereana (Colombia): los municipios...

Gráfico No. 2

Editores / Productores

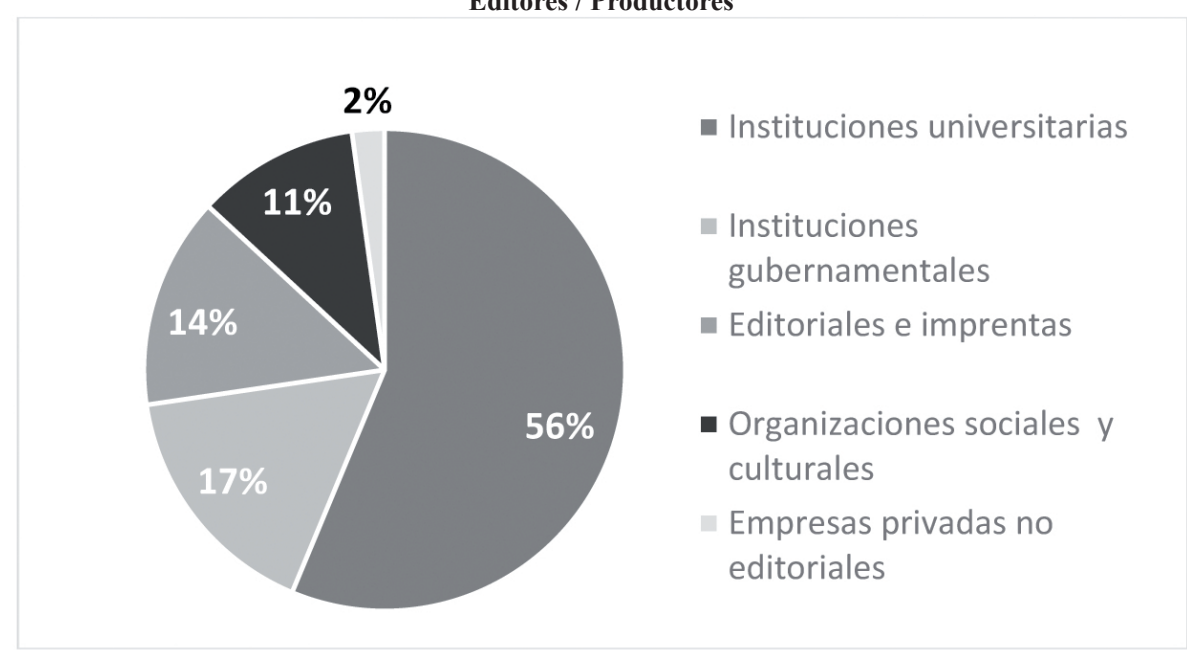

Fuente: elaboración propia a partir de bases de datos bibliográficas

Resalta, sin embargo, la poca vinculación de parte de las instituciones territoriales del Estado (alcaldías, gobernación, concejos, etc.) en la promoción y difusión de investigaciones sobre sus propias circunscripciones. También el desinterés por apoyar a las universidades en esta tarea, pues son muy pocas las obras hechas con el apoyo o en coedición con dichas entidades. Esto dice mucho de la subvaloración que la historia recibe de parte de dichos organismos territoriales y los sectores políticos y administrativos, al no considerarla necesaria ni "útil". Asimismo, de la ignorancia de los gobernantes sobre la importancia de la investigación social para la planeación y proyección administrativa.

Por otro lado, como ya se dijo, buena parte de estos trabajos son tesis de grado $(51 \%)$, de programas de pregrado y maestría en historia o ciencias sociales y, por tanto, son muy poco conocidos por el público, lo cual redunda en la pervivencia de una amnesia o distorsión de la conciencia histórica de la sociedad santandereana.

En conclusión, se resalta una vez más el divorcio que existe entre mundo académico y entidades gubernamentales. La universidad produce conocimiento, pero este no es aprovechado por los entes territoriales ni llega a la población. Y no hace falta realizar encuestas para saber que los habitantes de la zona no tienen mayor idea de que existe ya mucha información histórica sobre su territorio y que pueden acceder a él de manera relativamente fácil. 


\subsection{Preeminencia de Barrancabermeja como objeto de investigación}

Gráfico No. 3

Contexto geográfico

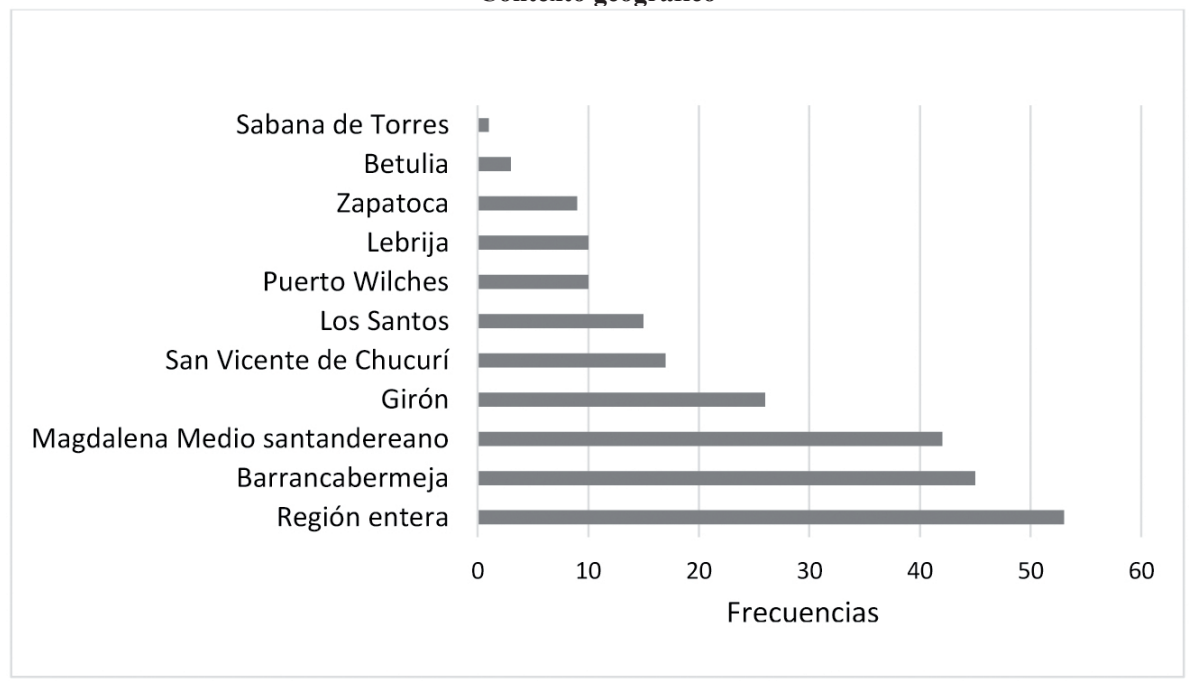

Fuente: elaboración propia a partir de bases de datos bibliográficas

Barrancabermeja y la región circundante ha sido la ciudad más estudiada entre los municipios de la subregión. Además de concentrar una parte significativa de la población, esta ciudad, dada sus características como puerto petrolero y centro de movimientos sociales y zona neurálgica del conflicto armado reciente, ha llamado la atención de los investigadores, especialmente a partir de la década de 1980. La región del Magdalena Medio santandereano, por razones parecidas, ha sido también objeto de un interés predominante. Sin embargo, dicho enfoque como centro de movimientos sociales y violencia no ha permitido abordar otras temáticas muy importantes para la comprensión de una historia global de la ciudad -región, tales como los aspectos culturales, la vida cotidiana, la religiosidad, la economía, la configuración social, la familia, la salud, etc.

Puerto Wilches, por su parte, también ha sido estudiado casi exclusivamente por su vinculación con los procesos de construcción de vías férreas en la segunda mitad del siglo XIX y primera del XX, los cuales fueron claves en el jalonamiento poblacional y económico de la subregión. Nada más ha interesado de la historia de dicho municipio.

Sobre el municipio de Los Santos solo se ha generado interés por su pasado lejano, es decir, porque en sus tierras se han encontrado yacimientos arqueológicos que vinculan este territorio con centros de poblamiento prehispánico; pero no ha interesado mucho su historia posterior al siglo XVI.

Los municipios menos estudiados son: Zapatoca, Betulia y Sabana de Torres. Ello, a pesar de que el primero en los siglos XIX y comienzos del XX fue un centro 
Hacia un balance de la historiografía regional santandereana (Colombia): los municipios...

de colonización hacia el valle del Río Magdalena, y el segundo es el epicentro de la nueva represa de Hidrosogamoso. Sabana de Torres ocupa el último lugar de la lista, con una sola publicación, sobre la relación entre conflicto armado y tierras.

Así, cada lugar ha estado signado directamente por una temática y época particular de enfoque, de manera que la mayor parte las poblaciones de la zona solo han sido importantes en tanto que "escenarios" o estudios de caso de procesos macro que han interesado al investigador, que normalmente es externo a dichos municipios. Pero no han interesado mucho como territorios y poblaciones en sí mismos.

\subsection{Los siglos XIX y XX son las épocas más estudiadas}

Los periodos 1902-1960 y 1810-1902 son los que abarcan la mayor parte de las investigaciones de naturaleza histórica sobre la zona del Río Sogamoso. En un segundo lugar, más lejano se encuentran los periodos 1960-1990, 1990-2017, seguido de cerca por el periodo colonial (1538-1810). En un último, pero comprensible lugar, se encuentra el periodo prehispánico. Eso, por la ausencia de fuentes y por la dificultad para estudiarlo. ${ }^{9}$

La preferencia por estos periodos de tiempo se explica por las temáticas que han interesado a los investigadores: colonización, poblamiento, movimientos sociales ligados a la explotación petrolera y luego, conflicto armado. El siglo XIX ha suscitado gran interés en la historiografía regional santandereana, pues no pocos investigadores lo han visto como una especie de época fundacional, debido al proyecto liberal radical que nació y fracasó en estas tierras, y por ser la época de inicio de colonización de las zonas bajas, especialmente en torno a los ríos Magdalena y Sogamoso, que hoy día jalonan la economía departamental. En cuanto al periodo colonial, las investigaciones también se interesan predominantemente por los procesos de poblamiento.

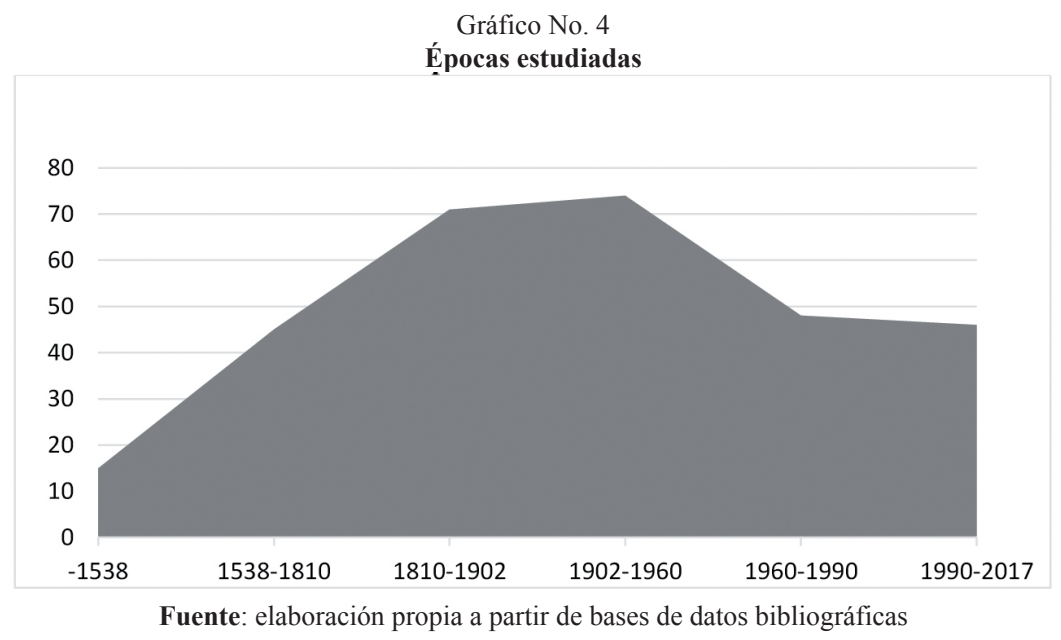

\footnotetext{
${ }_{9}^{9}$ Para abordar el periodo prehispánico se requieren esfuerzos interdisciplinarios que incluye la participación de la arqueología, la geología y la etnohistoria, lo cual encarece y dificulta las investigaciones.
} 
En cuanto a la primera mitad del siglo XX, hasta los años 60 corresponde a los años "dorados" del movimiento obrero, del cual Barrancabermeja fue un centro muy importante a nivel nacional. Luego, el desencadenamiento del conflicto armado entre guerrillas, estado y paramilitarismo en la región también ha suscitado el interés, mucho más reciente, y a la vez creciente de investigadores sociales interesados en la "historia del tiempo presente" y la llamada "memoria histórica", en las cuales es imperativo la necesidad de recuperar la historia de los excluidos y las víctimas para generar procesos de verdad, justicia y reparación. Expondremos a continuación, de forma más detallada, el núcleo de este balance: los intereses temáticos que explican dichas escogencias temporales.

\section{Análisis interno: temáticas predominantes}

Gráfico 5

Temáticas predominantes

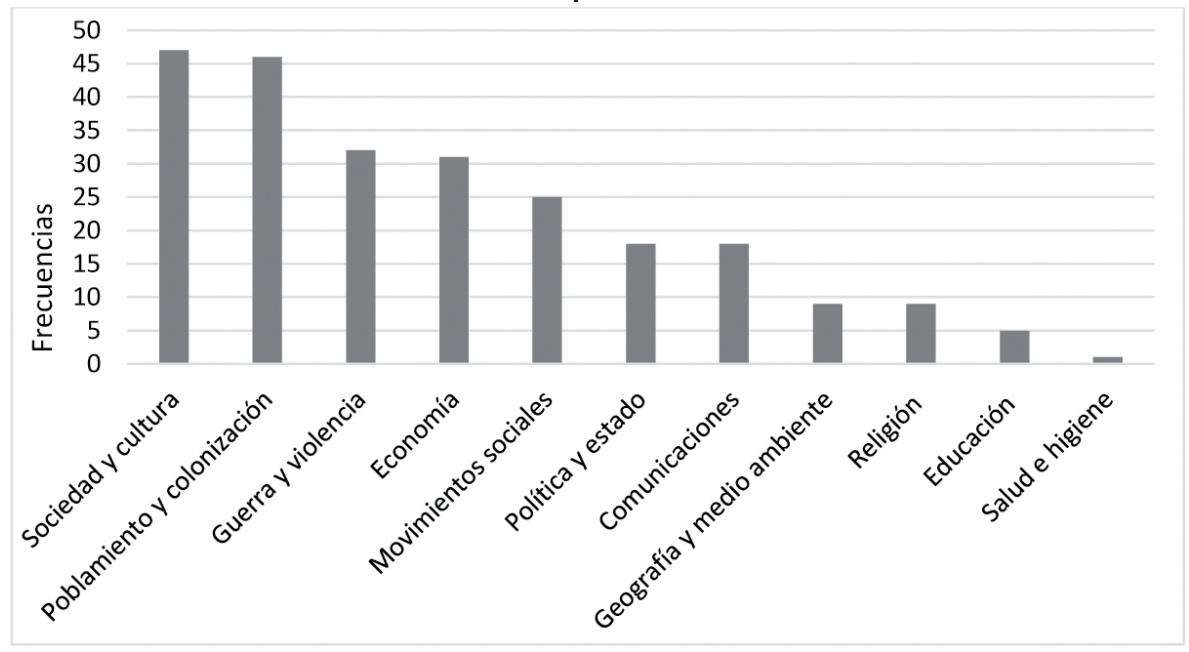

Fuente: elaboración propia a partir de bases de datos bibliográficas

La gráfica 5 muestra que las temáticas más estudiadas han sido las relacionadas con asuntos sociales y culturales, seguidas muy de cerca por cuestiones sobre poblamiento y colonización. En un tercer lugar se encuentra el conflicto armado (contemporáneo, de mediados del siglo XX y las guerras civiles del siglo XIX); a continuación vienen los temas económicos, movimientos sociales, asuntos políticos y de estado, comunicaciones y medio ambiente. Las temáticas menos estudiadas tienen que ver con lo religioso, lo educativo y sorprende la casi inexistencia de estudios sobre temas de salud, higiene y cuestiones médicas.

\subsection{Sociedad y cultura}

Sobre las cuestiones sociales y culturales (familia, grupos étnicos, pobreza, demografía, fiestas, folclor, cultura campesina, indígenas, alimentación, bebidas embriagantes, etc.) habría que decir que la mayor parte de los estudios que las 
incluyen hablan del departamento entero, o de la subregión en general, o se enfocan en los municipios andinos (Girón, Los Santos, etc.) mientras que aquellos ubicados en el llamado Magdalena Medio son poco abordados en este sentido. Buena parte de las investigaciones sobre esta temática abordan largas temporalidades, que van de al menos medio siglo, a varias centurias; también se observa una distribución equilibrada en distintos periodos: prehispánico, Colonia, siglo XIX y XX.

En cuanto a las subtemáticas más frecuentes, resaltan los estudios sobre grupos poblacionales, ${ }^{10}$ especialmente de los indígenas ${ }^{11}$ Guanes $^{12}$ y Yariguíes. $^{13}$ Esto se explica, de un lado, por los mitos que existen alrededor de la cultura Guane, considerada en el imaginario popular como el sustrato étnico de la población santandereana (particularmente de la zona andina) y por la resistencia que los Yariguíes ofrecieron a los procesos de colonización y su correspondiente etnocidio llevado a cabo en los siglos XIX y XX, cuyo recuerdo busca ser integrado recientemente a la memoria popular y oficial fundante de la identidad subregional. Buena parte de estos estudios, especialmente los relacionados con los Guanes, son hechos por arqueólogos en su mayoría foráneos a la región, aunque en los últimos años el arqueólogo Leonardo Moreno González ha publicado artículos y libros productos de sus excavaciones sobre sociedades prehispánicas que habitaron la Mesa de los Santos, lanzando interesantes hipótesis que merecen atención. Otros grupos poblacionales estudiados, pero en mucha menor proporción son los afrodescendientes (incluyendo esclavos coloniales) y los campesinos, ambos integrantes visibles de la sociedad rivereña de los ríos Magdalena y Sogamoso. ${ }^{14}$

Por otra parte, hay una obra sobre inmigración extranjera (alemana) en el siglo XIX, compuesta por el académico Horacio Rodríguez Plata, aunque hace ya varias décadas que se publicó y un artículo sobre el mismo tema un poco más reciente. Ambos se refieren a otro fenómeno que se guarda muy bien en la memoria popular de varios de los municipios de nuestra región: los inmigrantes alemanes en el siglo XIX y sus acciones, varias de ellas míticas, gracias a la tradición oral y a la literatura, con obras como La otra raya del Tigre, del escritor bumangués Pedro Gómez Valderrama. Cuestiones sobre el folclor, la alimentación (particularmente sobre las hormigas culonas) las bebidas alcohólicas, y estudios de familia y honor (en la época colonial) completan el cuadro de las temáticas sociales estudiadas por los investigadores.

\footnotetext{
${ }^{10}$ Se halló un interesante trabajo de demografía histórica sobre el caso de Girón. Este tipo de investigaciones son difíciles de hacer, pues se requiere paciencia, constancia, detalle y dedicación.

${ }^{11}$ No hay casi análisis globales de los sectores indígenas durante la época colonial en la zona. Entre los pocos que existen se encuentra un interesante estudio realizado por Armando Martínez, sobre el régimen social al que fueron sometidos a partir del siglo XVIII.

${ }^{12}$ Entre los primeros trabajos publicados sobre los guanes se encuentran estudios aficionados, pero a partir de los años 80 las investigaciones son realizadas en su mayoría por profesionales.

${ }^{13}$ Los estudios sobre los Yariguíes o Yareguies son menos, en comparación con los realizados sobre los Guanes. En su mayoría provienen de las últimas décadas

${ }^{14}$ Sobre esclavos y afrodescendientes la bibliografía es escasa y de regular calidad. Sobre cultura campesina los estudios son aún más escasos, pero más elaborados.
} 


\subsection{Colonización, poblamiento y configuración urbana}

La subregión ha interesado por su tardía colonización (a partir de mediados del siglo XIX) y por haberse convertido tras el advenimiento de la era republicana, en una zona clave para la economía, de manera que fue objeto de esfuerzos en construcción de caminos, fundación de pueblos que ayudaran a ampliar la frontera agrícola. Quizá los trabajos más elaborados y documentados son los de este tipo. Los primeros intentos se llevaron a cabo en los años 30 y 40 del siglo XX; allí se publicaron las obras de José Manuel Rojas y José Fulgencio Gutiérrez, que aún hoy siguen siendo importantes como fuente de datos. Otra obra importante -lamentablemente nunca publicada- la realizó el dominico Fr. Enrique Báez en esos mismos años. Se denomina "Parroquias de Santander" y permanece inédita en el Archivo Provincial de la Orden Dominicana, en Bogotá $^{15}$. Sin embargo es en los años 80 y 90 que se aunaron dos procesos: por una parte, el creciente interés que despertaban algunas regiones de Santander para investigadores del centro del país interesados en procesos de poblamiento y colonización y por otra, el esfuerzo-lamentablemente trunco- de realizar-desde el mundo universitario local- una historia regional sistemática de la región santandereana.

Respecto a la primera línea, los trabajos van desde la época colonial y el siglo XIX a un interés por el Magdalena Medio, como zona de conflictos sociales y políticos. Por ello se enfatiza invariablemente en la relación entre colonización petróleo - movimientos sociales - conflictos agrarios - violencia y conflicto armado.

En cuando al segundo grupo de trabajos, estos tienen como epicentro la Universidad Industrial de Santander y se enmarcaban en un plan, dirigido por los profesores Armando Martínez Garnica, Amado Guerrero y Jairo Gutiérrez Ramos, de realizar una completa historia regional del llamado "Gran Santander" (Santander y Norte de Santander). Para ello se concibió necesario iniciar con la configuración de las subregiones y los procesos de poblamiento.

Este esfuerzo produjo varias obras sobre colonización y poblamiento que hoy día constituyen referentes básicos para el estudio de cualquier proceso históricosocial en el departamento en general, y en la región en particular. La primera obra sintética fue publicada en 1994 y se denomina "historia de la subregionalización de los santanderes", obra descriptiva basada en abundantes fuentes primarias, aunque carente de interpretaciones profundas, que sin embargo, no le impide constituirse en obra básica para la comprensión de estos procesos. A continuación se publicaron seis libros derivados de este mismo proyecto (uno por provincia) ${ }^{16}$ donde se exponen los procesos fundacionales de todos los municipios de Santander. Aquellos ubicados en la región del Río Sogamoso se incluyeron en los libros sobre la entonces Provincia de Mares ${ }^{17}$ y la Provincia de Soto.

\footnotetext{
${ }^{15}$ El valor de esta obra es que compendia, de forma poco ordenada, numerosas fuentes primarias tomadas de archivos parroquiales y civiles, muchas de cuyos originales han desaparecido ya.

${ }^{16}$ Soto, Guanentá, Comunera, García Rovira, Vélez y Mares.

17 Rebautizada en 2016 como Provincia de Yariguíes.
} 
Estas obras resaltan que la mayoría de estas poblaciones surgieron en tiempos posteriores a la época colonial, producto muchas veces de iniciativas de colonos y eclesiásticos interesados en acceder a las ricas pero malsanas tierras bajas, motivados por intereses económicos (mineros, pecuarios, forestales, etc.). Una síntesis de esos mismos trabajos se encuentra en el libro "Pueblos de Santander", publicado en 1994. Aunque el proyecto se detuvo, varios investigadores continuaron trabajando por su cuenta, con el apoyo de estudiantes y egresados de la carrera de historia de la UIS, enfatizando en aspectos económicos y sociales del proceso y produciendo obras que, basadas en los resultados del proyecto mencionado, amplían sus fuentes, ${ }^{18}$ sus observaciones y su marco interpretativo, yendo más allá de la descripción y proponiendo hipótesis.

Todas estas obras concluyen en que la fundación de la mayor parte de los municipios del centro y oeste de Santander (varios de los cuales se ubican también en la cuenca del río Sogamoso) son fruto de procesos de colonización que buscaban ampliar la frontera agraria y conectar lo que inicialmente era la provincia del Socorro y el sur de la provincia de Pamplona con el río Magdalena y a través de este, con el exterior del país. Para ello había que "conquistar" las, hasta entonces indómitas selvas de la región y adaptarse a unos climas poco salubres. Este proceso se habría dado en por lo menos tres etapas, que seguían cada una un camino particular, generando el nacimiento de un grupo de parroquias - municipios: Girón, Lebrija, Los Santos y Zapatoca en la primera; Betulia y San Vicente de Chucurí en la segunda; y Barrancabermeja, Puerto Wilches y Sabana de Torres en la tercera. La naturaleza conflictiva que tuvo estos procesos (sobre todo los últimos) apenas comienza a ser abordada por los investigadores. En todo caso, consideramos que, gracias al esfuerzo realizado en las décadas de 1990 y parte del 2000, se ha avanzado mucho en el conocimiento sobre las lógicas y características de poblamiento de los municipios santandereanos en general y de la región del Magdalena Medio y de la cuenca del Sogamoso en particular.

En esta misma lógica de comprensión de un proceso global regional, se han venido estudiando casos particulares. El más trabajado es indiscutiblemente el de la ciudad de Barrancabermeja. Ya en la década de 1940 inician los primeros estudios sobre esta población, escritos en la línea de memoria y reminiscencia, constituyéndose casi en un testimonio de primera mano de la vida social en la primera mitad del siglo XX. Solo hasta finales de los años 70 la ciudad cobra interés para los académicos, inicialmente con pequeñas monografías de grado hoy inéditas; luego, a mediados de la década de 1980 Rafael Núñez Ospino publica una obra de regular calidad que sintetiza la historia de la ciudad y en la cual se echa mano de algunos testimonios orales. ${ }^{19}$

\footnotetext{
${ }^{18}$ En algunos trabajos, como los del profesor Emilio Arenas ("El Viaje" y "Siete Leguas") se incluyen fuentes orales, omitidas en los primeros estudios.

${ }^{19}$ Publicada en 1987, la obra tuvo una segunda edición en 1997, editada por la Alcaldía de Barrancabermeja, en homenaje póstumo al autor.
} 
La que constituye quizá la obra más completa y profunda sobre el origen de Barrancabermeja se publicó en la década siguiente. Su autor es el francés Jacques Aprile, historiador urbano, y se intitula "Génesis de Barrancabermeja". Esta obra ha logrado difundirse entre los especialistas, no solo de la historia regional, sino de la historia de la ciudad en Colombia, pese a las limitaciones de difusión que el tipo de edición tuvo. Más recientemente Diego Fernando Otero publicó otro texto que no agrega mucho a lo que ya se conocía sobre el nacimiento de la ciudad.

Todos estos trabajos abordan, casi sin excepción, los mismos aspectos: antecedentes del territorio donde nació la ciudad, la concesión petrolera llamada "de Mares" que dio pie a las explotación petrolera y al nacimiento del municipio, la migración de obreros buscando trabajo en las petroleras establecidas en la zona y los movimientos sociales derivados de dicha proletarización. El texto de Aprile incorpora además un interesante apartado sobre el etnocidio de los Yariguíes producto de dicho proceso colonizador.

Tras aclarar lo relacionado con el origen de Barrancabermeja, una nueva generación de historiadores - profesionales- han venido trabajando sobre la urbanización y el crecimiento de dicha ciudad. Así, mientras Javier Serrano Besil estudia el crecimiento urbano en la primera mitad del siglo XX, Carlos Flórez y Luisa Castañeda investigan lo mismo pero otra época: los años 70 y 80, caracterizada por el aumento de la migración campo - ciudad por cuestiones económicas y por la violencia, con el correspondiente surgimiento de tugurios e invasiones.

Otros municipios que han sido estudiados dentro de las lógicas de comprensión de procesos de colonización y poblamiento en distintas épocas son: San Vicente de Chucurí y Girón. Así, Daniel Alfonso León, presentó el caso de San Vicente en dos interesantes trabajos de grado (de pregrado y maestría en historia respectivamente) a partir de los cuales ha publicado algunos artículos. En estas obras, basadas en abundantes fuentes primarias, se estudian tres elementos del proceso: la construcción de caminos, la compra venta de tierras y las actividades de familias y autoridades civiles. Se identifican además los liderazgos y las estrategias utilizadas por estos grupos ascendentes para hacerse con las tierras y dominar el panorama político y económico. Por su parte, Ivonne Duque trabajó el caso de Girón, en la segunda mitad del siglo XX, tratando de comprender el proceso que llevó al crecimiento periférico de un municipio que dejó de ser el tranquilo pueblo tradicional a convertirse en una ciudad - dormitorio de Bucaramanga.

Son escasos los estudios que intenten realizar un esfuerzo monográfico, es decir, investigaciones detalladas sobre la historia de un pueblo. Los únicos municipios abordados han sido San Vicente de Chucurí, Girón, Los Santos y Zapatoca. La característica de estas obras es que normalmente fueron hechas por paisanos que buscaban exaltar las cualidades de estos lugares, utilizando un estilo anecdótico, cronológico y con poca contextualización y sentido crítico de la historia que se narra. Estamos entonces, ante una carencia sensible de estudios completos, integrales, críticos y analíticos, sobre la historia de los municipios de la cuenca del Río Sogamoso y en general, del departamento de Santander. 
Hacia un balance de la historiografía regional santandereana (Colombia): los municipios...

\subsection{Guerra y violencia}

Infortunadamente, la región que nos ocupa ha sido conocida en las últimas décadas, ante todo por ser escenario de violencia y luchas armadas, de modo que las investigaciones sobre este tema han sido importantes. Dos subtemas particulares han sido estudiados: en menor medida las guerras del siglo XIX por sus efectos en Santander y sobre todo el conflicto armado del siglo XX (especialmente las décadas de 1960, 1980, y 1990) escenificado en el Magdalena Medio santandereano. Por otra parte, resaltan por su ausencia los trabajos sobre la llamada época de la "Violencia" o guerra civil entre liberales y conservadores, desarrollada en las décadas de 1940 y 1950, cuya memoria de dolor y sufrimiento -que fue enorme en la región- se desvanece cada vez más en el olvido.

Sobre las guerras decimonónicas los trabajos son más bien pocos. Podemos destacar la compilación de textos que combinan crónica, memoria histórica y literatura, denominado "La guerra de los Mil Días en las letras santandereanas", en el que se destacan ensayos de Eduardo Rueda, Elisa Mujica y Joaquín Mantilla, entre otros. Estudios más recientes investigan sobre otras guerras del siglo XIX, aquellas que podemos considerar como "olvidadas" y que sin embargo afectaron sensiblemente al territorio. Estos trabajos se llevaron a cabo como fruto de un proyecto de investigación llevado adelante por la Escuela de Historia de la UIS, bajo la dirección de los profesores Juan Alberto Rueda y Armando Martínez, entre otros. Así, se estudió, para el caso santandereano, las guerras de 1859-62 y la guerra de 1876-77. El primero, llevado a cabo por Carolina Becerra en sus aspectos sociales, políticos y bélicos; el rol jugado por las guerrillas, el clero, las mujeres y la financiación del conflicto. El segundo, realizado por Diego Andrés Jaimes, aborda la guerra de 1876-77, una de las más cruentas del siglo, no solo en sus aspectos militares, sino como un conflicto que involucró intereses políticos y económicos -no solo de combatientes y promotores, sino además, de personas externas- y del que es difícil hablar de un ganador absoluto.

Aparte de estas investigaciones, en su mayor parte inéditas, la producción historiográfica sobre la guerra y la violencia en la zona del Río Sogamoso ha crecido en las últimas décadas, por obvias razones: se trata de un conflicto extenso, complejo y sobre todo vigente hasta la segunda década del siglo XXI, cuyas consecuencias afectan hoy día la vida de los pobladores de los municipios de la zona y de cuyas causas y desarrollo ha ocupado no solo a historiadores, sino, sobre todo, a sociólogos, politólogos, y otros cientistas sociales.

A pesar de la importancia y gravedad del conflicto, solo hasta 1989 se publicaron los primeros estudios de tipo histórico sobre la región, originados en centros de investigación de Bogotá. El primero es un artículo de Alejo Vargas que busca hallar continuidades y rupturas de tres momentos de la violencia política de Colombia a través del estudio de caso de San Vicente de Chucurí, en el periodo de 1929 y 1964: la insurrección bolchevique de 1929, las guerrillas liberales lideradas por Rafael Rangel en los años cincuenta y el surgimiento del Ejército de Liberación Nacional (ELN) en los años sesenta. 
A partir de entonces se han desarrollado varios trabajos de grado e investigaciones, producidas en su mayor parte por centros de investigación externos a la región, destacándose en ello el Centro de Investigación y Educación Popular CINEP- entidad que tiene vínculos con la zona. Al parecer, el estudio de la violencia y el conflicto ha sido menos interesante o factible para las entidades ubicadas en la región y en el departamento, que para entes externos a ella.

Dos son las poblaciones estudiadas de forma particular: San Vicente de Chucurí, por ser este municipio escenario de arremetidas del ELN en los años 80 y de nacimiento de grupos paramilitares en esa misma década y Barrancabermeja, centro de luchas de guerrillas y paramilitares en los años 90, que llevó a la ciudad a las horas más aciagas de su historia. Otro grupo se investigaciones abordan toda la región del Magdalena Medio y son más generales. Tales municipios y dicha región se han convertido en verdaderos "casos emblemáticos" para los investigadores del conflicto armado colombiano.

El objetivo de estas obras es comprender en primer lugar el origen, desarrollo y objetivos del paramilitarismo en la región, estudiando además la relación que tenía con intereses económicos de hacendados y empresarios en la región y cómo permeó el Estado y la administración pública. Se investiga además, los procesos de criminalidad y victimización, las masacres perpetuadas y finalmente las resistencias llevadas a cabo por la población civil. Es notable y diciente el desinterés por estudiar las guerrillas de izquierda y su accionar en la región, salvo las menciones que se hacen en el libro de Milton Hernández sobre la historia del ELN (obra por lo demás apologética y propagandística) y en el artículo Jorge Meléndez sobre la relación de la muerte de Camilo Torres Restrepo y el territorio de los municipios de El Carmen y San Vicente de Chucurí.

\subsection{Economía}

Otra temática que ha suscitado significativo interés en los investigadores ha sido la economía. Para empezar, vale decir que buena parte de los trabajos que mencionaremos en este campo han sido realizado por estudiantes y egresados de la Escuela de Historia de la UIS, motivados y/o con la ayuda de sus profesores, en especial William Buendía y Amado Guerrero, quienes se han preocupado por inculcar en los estudiantes la necesidad de investigar la economía de la región. Por otra parte, hay que decir que, pese a ello, prácticamente no se han realizado estudios históricos generales sobre la economía regional o subregional. Solo existe uno, sobre el siglo XIX, el cual puede considerarse un clásico de la historiografía, no solo regional, sino nacional, por su profundidad y nivel analítico. Se trata del estudio de David Church Johnson intitulado "Santander, siglo XIX, cambios socioeconómicos", que a más de 30 años de su publicación sigue siendo un referente obligado para conocer la economía de la época. Aparte de este caso, los demás textos abordan aspectos parciales, aunque lleguen a abarcar distintos periodos, incluyendo el prehispánico, como es el caso del interesante estudio de Pierre Raymond, cuya cobertura alcanza a vincular a la provincia de Girón, siendo una historia de la industria textil, del cultivo del algodón y su manufactura en Santander, hasta el presente. 
Un tema constante en la producción historiográfica sobre la economía regional explora los asuntos agrarios y relacionados con transacciones de tierras y conflictos por ellas. Se explica este interés por la configuración histórica de la zona, ligada a procesos de colonización, y curiosamente, siguen el ritmo de dichos procesos. La época más tardía trabajada es el siglo XVIII: Jesús Bohórquez estudia el proceso de ampliación de frontera en los valles bajos, así como el mercado de tierras y su relación con los cultivos de caña, cacao y ganadería. Concluye cómo con el comercio del cacao, se inicia un desplazamiento de la frontera de las tierras bajas, y se ve que los ritmos del mercado difieren en las zonas altas y bajas. Al llegar al siglo XIX y especialmente a la bisagra ente este siglo y el XX, las investigaciones aumentan: Esperanza Villamizar realiza un estudio descriptivo sobre la adjudicación de tierras baldías para colonización en la región del Río Sogamoso, Clara Inés Carreño relaciona el movimiento de tierras con la construcción de los caminos de los ríos Lebrija y Sogamoso. Ligado a procesos similares, Ivonne Marcela Duque estudia detalladamente la compra venta de tierras en Girón a fines del siglo XIX y para épocas más recientes, Diana García Pérez trabaja en detalle el proceso de compra y venta de tierras en Lebrija y su zona rural y lo relaciona con el contexto de migraciones y desplazamientos producidos por la violencia bipartidista y el desarrollo económico de ciudades como Bucaramanga. Alexander Duarte y Raúl Contreras continúan esta lógica y estudian la relación entre conflicto armado y dinámica de uso de suelos en Barrancabermeja, Sabana de Torres y Puerto Wilches, en los últimos años del siglo $\mathrm{XX}$. Vemos entonces a un grupo interesante de investigaciones que, reunidas, ofrecen una perspectiva del conflictivo proceso de adquisición y manejo de las tierras en la región, y que es considerado por los estudiosos como una de las fuentes del conflicto armado experimentado por la misma en el siglo XX. Lamentablemente la mayor parte de dichas investigaciones no se han publicado bajo la forma de libros o artículos, aunque son accesibles vía internet.

Otras subtemática que han interesado a los investigadores es la historia de productos agrícolas, sus precios, su consumo y su impacto social y económico. Así, hay algunas investigaciones sobre el café, el arroz, la carne, la caña de azúcar, el aguardiente y productos varios ligados a la colonización de la región del Sogamoso. Al respecto merece resaltarse el original artículo de Jesús Bohórquez y Gabriel Palacio en torno a las prácticas de circulación y consumo en las cuencas de los ríos Sogamoso y Lebrija en el siglo XVIII. Se abordan las redes establecidas por ciertos comerciantes; se caracterizan las relaciones entre economía minera y agraria y la importancia de esta última en la activación de una corriente de consumo fuerte durante el siglo XVIII. Se discute el problema de la moneda y la manera como los productos circulaban con o sin ella; y se describe además el tipo de mercancías que eran consumidas en las zonas rurales. Trabajos de este tipo merecen ser continuados y profundizados.

El sector minero ha merecido alguna atención -aunque precaria a nuestra manera de ver- especialmente el petróleo, producto bandera que ha ayudado a configurar el "rostro" subregional en el último siglo. En 1979 María Oliva Méndez y Rosa Celina Ramírez escriben su trabajo de grado sobre la historia del petróleo, ligada a la fundación y desarrollo de Barrancabermeja; luego, en los años 80, Miguel Ángel 
Santiago publica un libro de historia de la concesión de Mares, el origen y desarrollo de la explotación petrolera en la zona con la Tropical Oil Company y más adelante, con el nacimiento de Ecopetrol. Edgar Andrés Caro insiste también en este punto, con un artículo suyo sobre la reversión de la concesión de Mares y la nacionalización de la explotación petrolera en Barrancabermeja. Finalmente, Silvia Juliana Becerra estudia las relaciones entre economía petrolera, neoliberalismo y paramilitarismo. Vemos que la economía petrolera en la subregión aún espera historiadores que la estudien y nos ayuden a comprender no solo la relación que tiene con el nacimiento y desarrollo de Barrancabermeja o con los movimientos sociales -perspectiva preferente, como se verá- sino su dinámica interna, sus dinámicas e impactos en el desarrollo económico.

Pero los estudios no se han orientado únicamente en torno a procesos; también se ha tenido en cuenta a protagonistas de los mismos. En la historia económica colombiana se ha venido trabajando con cierto interés la historia empresarial, de manera que algunos trabajos han incluido a la región. Específicamente se ha investigado torno a los casos de Bartolomé Rugeles y Geo Von Lengerke, quienes invirtieron y trabajaron por la colonización de la subregión del río Sogamoso a través de la construcción de caminos y vías férreas, arruinándose en el intento, debido a la crisis que afectó la economía regional a fines del siglo XIX y que, según estos autores, llevó a Santander al declive como región económica del país. No deja de ser curioso que estas investigaciones sobre empresarios locales se hayan concentrado en aquellos que no prosperaron, dejando a un lado a quienes que, ya en el siglo $\mathrm{XX}$, se enriquecieron y condujeron, con todas las consecuencias que ello tuvo, las riendas económicas de la región.

Las instituciones públicas y su funcionamiento económico apenas han recibido algún interés por parte de la historiografía. Solo encontramos dos publicaciones: una sobre las finanzas del cabildo de Girón en el siglo XVIII, y otro sobre las finanzas del estado Soberano de Santander, durante el periodo radical, en el siglo XIX. De manera que aún estamos en ascuas para comprender en el devenir histórico asuntos tan cruciales como los ingresos y gastos públicos, su manejo, la corrupción ligada a ello, la cooptación del estado por parte de intereses privados, etc.

\subsection{Vías de comunicación}

Ligado a la economía se encuentra lo relacionado con la construcción y desarrollo de vías y medios de comunicación tema que, sin embargo, hemos querido tratar aparte. Una gran encrucijada de los siglos XIX y XX tuvo que ver con la forma de comunicar mejor los principales centros urbanos, con los mercados internacionales. El gran obstáculo era una geografía empinada, montañosa, junto a zonas selváticas muy cálidas y húmedas. Todas las miradas se dirigían al río Magdalena, principal arteria fluvial del país, que conducía a la costa norte y de ahí, al exterior. Como subsidiarios, se pensó en utilizar afluentes como los ríos Lebrija, Sogamoso, o el camino real atravesando las montañas de Galán, Zapatoca, Betulia y San Vicente. Luego, se pensó en construir una vía férrea hacia Puerto Wilches. A mediados del siglo XX se abandonaron estos proyectos y todo se orientó en torno a las carreteras y 
los aviones. Vale decir que ninguno de estos proyectos se desarrolló en condiciones óptimas y apenas se privilegió la conectividad de las principales ciudades, quedando la gran mayoría de las poblaciones de segundo y tercer orden, semiaisladas en sus valles, llanuras o recovecos andinos.

La potencialidad de los ríos Lebrija, Sogamoso, Carare y Opón nunca fueron aprovechadas: el ferrocarril fue saqueado, quebrado y destruido y las carreteras que se abrieron durante muchos años eran simples "trochas" intransitables en épocas de invierno. El Magdalena Medio apenas comenzó a conectarse medianamente con al resto de Santander a partir de los años 70 del siglo XX y aún en pleno siglo XXI existen zonas poco accesibles vía terrestre. Ir de Barrancabermeja y la mayoría de los municipios de la región del Río Sogamoso, a la capital del departamento implicaba, hasta hace algunos años, hacer un viaje largo, tortuoso, agotador. Todo ello hace de Santander uno de los departamentos con las peores vías de comunicación de la zona andina, que no responden a su importancia. Buena parte de esta historia es contada, descrita y analizada por varias publicaciones y obras inéditas, las cuales se han concentrado en dos aspectos: la construcción de caminos al Magdalena en el siglo XIX y del ferrocarril a Puerto Wilches en el siglo XX.

Emilio Arenas es, hasta ahora, el único investigador que nos ofrece un panorama general, con su libro "Siete Leguas", y que a su vez es una síntesis de información publicada en otras obras suyas sobre poblamiento en Santander, agregando ahora particulares e ingeniosas interpretaciones, más aportes de la historia oral. Arenas se refiere a tres procesos constructivos de camino, que generan a su vez el nacimiento de la mayoría de los municipios de la región. En el primero, se buscaba ampliar la frontera agrícola desde la provincia del Socorro y conectar esta con el río Magdalena. Para ello se recurrió a la construcción de un camino real, que finalmente concluye el alemán Geo Von Lengerke, y que recorrió los actuales municipios de Galán, Zapatoca, Betulia, San Vicente de Chucurí y Barrancabermeja. En el segundo, se buscó ampliar la frontera agrícola entre Bucaramanga y Puerto Wilches, recurriéndose a la construcción del Ferrocarril de Santander, que implicó el nacimiento de poblaciones como Puerto Wilches y Sabana de Torres. El tercer proyecto se orientó a comunicar Bucaramanga y Girón con Barrancabermeja, su puerto petrolero y el Río Magdalena y la Costa Caribe, a través de la construcción de carreteras, que involucraron a las poblaciones de Lebrija y el Playón.

Clara Inés Carreño y Jesús Bohórquez, quienes se han destacado por sus aportes a la historia de la colonización de la cuenca del río Sogamoso, aportan ahora un interesante estudio la comprensión de la historia social y cultural de los viajes comunicaciones en los siglos XVIII y XIX, acercándose a las vivencias, los sentimientos, los ritmos, las velocidades, las estacionalidades, los recorridos y cómo los intereses económicos de los hombres los impulsan a sortear los infranqueables espacios en que se encontraban. Por su parte, Álvaro Pablo Ortiz, Clara Inés Carreño y Cintya Maldonado estudian los proyectos empresariales del alemán Geo Von Lengerke, quien se constituyó en un hito para la historia de la zona del Río Sogamoso por su papel en la colonización y construcción de caminos reales. Daniel Alfonso 
León, continúa con sus aportes al conocimiento de la construcción y desarrollo del camino real del Socorro al Magdalena por la serranía de los Yariguíes, con su documentado artículo derivado de su tesis de maestría.

La historia del ferrocarril de Santander (o de "Puerto Wilches") es quizá uno de los aspectos más trabajados de la historiografía de la región, con una decena de publicaciones entre artículos, libros y tesis de grado. Si bien los primeros estudios inician en 1914, cuando El ingeniero Alfredo Ortega publicó, por partes su "Historia del ferrocarril de Puerto Wilches", aún inconcluso, en la revista "Anales de Ingeniería", fue hasta la década del 2000, cuando se genera la mayor parte de las investigaciones y publicaciones. El interés por este subtema se debe a que se trató de un proyecto que conllevó muchos problemas para su terminación (unos 70 años), que demandó muchos recursos, quebró a varios empresarios, desfalcó las arcas del Estado, y cuando finalmente se concluyó, ya estaba técnicamente obsoleto y el interés de los empresarios y los gobernantes se había dirigido hacia otros proyectos de vías.

Miguel Niño y Judith Bayona abren la serie de publicaciones, en 2002 con su libro "Del Camino de Paturia al Ferrocarril de Santander". Sergio Rangel publica "A paso de Yuma" en 2004. Augusto Olarte Carreño analiza los costos de construcción y señala la obra como discontinua y costosa. Zandalio Durán Rojas se enfoca en el nacimiento Puerto Wilches, en el marco de la construcción del Ferrocarril; David Centeno Báez y Leidy Johana Jerez Torres, repiten todo lo anterior y añade los costos sociales y humanos, su afectación por las crisis económicas y las guerras civiles, y se analiza críticamente el proyecto del ferrocarril dentro de los discursos de construcción de nación, de la época. Miguel Darío Cuadros profundiza en los costos económicos al estudiar el caso del empresario Bartolomé Rugeles y sus inversiones en el ferrocarril, que lo llevaron a la ruina, en el marco de una crisis económica generalizada. Juan Santiago Correa pone a prueba la tesis de que la discontinuidad y lentitud en la construcción del ferrocarril de Puerto Wilches tenía que ver con la crisis económica regional, al comparar la construcción de dicho ferrocarril con el de Cúcuta, encontrando contrastes y paradojas interesantes: de una parte, la línea de Cúcuta a Puerto Villamizar fue un modelo de eficiencia atípico en la construcción de los ferrocarriles del periodo al ser culminada en los tiempos y presupuestos asignados por ingenieros nacionales, mientras que, por otra, las líneas a la Frontera y al Sur, y el ferrocarril de Puerto Wilches expresaron, en mayor o menor medida, los excesos y defectos de las concesiones ferroviarias de la época. Estos ferrocarriles, asociados a la producción cafetera del oriente del país, reflejaron la esperanza del progreso en el siglo XIX, aunque no siempre esta se hizo realidad debido principalmente al convulso escenario político del departamento.

\subsection{Movimientos sociales}

Los movimientos sociales son otro tema que ha interesado mucho a la historiografía sobre la región, por razones por todos conocidas. Pese a que desde la década de 1920, la zona, especialmente Barrancabermeja, se ha destacado por ser cuna y nido de movimientos sociales, sindicales, cívicos, solo hasta la década de 1980 
fueron objeto de estudio por los historiadores, especialmente externos, quienes se interesaron en ella más que en sí misma, por lo que representaba para el país en el marco del estudio de las luchas sociales y el conflicto armado. Mauricio Archila, Carlos Hernández y José Yunis ${ }^{20}$ "descubrían" el movimiento obrero barranqueño como emblemático para el país, por su antigüedad, experiencias, luchas y logros conseguidos. Archila buscaba además, encontrar en dicho movimiento, una "cultura" radical, siguiendo en ello al historiador británico E. P. Thompson, ${ }^{21}$ que se configuraba y transformaba con el tiempo y que daba rostro a la ciudad. Esta tesis es mantenida en los años 90, con autores como Sonia Mercedes Rodríguez, quien continúa el trabajo iniciado por Mauricio Archila y también ve en Barrancabermeja la existencia de una "cultura radical", es decir, de la crítica, de la manifestación, de la organización social frente a prácticas patronales, opresoras y excluyentes. Alejo Vargas y Camilo Borrero tampoco se apartan de esta tesis cuando, al estudiar la colonización del territorio, enfatizan la característica conflictiva, rebelde y violenta del proceso. Para estos autores las luchas de los obreros petroleros se mezclaron con los procesos de colonización campesina y terrateniente de este territorio poco integrado a la nación y donde el Estado hacía poca presencia. Similar es la obra de María Teresa Arcila, y que, desde el Instituto Colombiano de Antropología, realiza una historia general del Magdalena Medio, enfatizando en los aspectos consabidos: colonización, petróleo, movimientos sociales, aspectos agrarios, violencia y conflicto armado.

Tras estas investigaciones, profundas y bien realizadas por autores externos a la región, más interesados que los locales por el estudio de estos aspectos de su historia, viene un aparente silencio por más de 10 años donde las investigaciones sobre movimientos sociales en la zona desaparecen, o al menos, no se publican. Curiosamente este tiempo coincide con el periodo de dominio paramilitar en la región, y esto no deja de ser diciente. De manera que es solo hasta 2005, tras la desmovilización de los principales grupos paramilitares, cuando se reanuda con fuerza esta línea. En principio, se realizan investigaciones que tratan de comprender la incidencia que tuvo el paramilitarismo en unión con agentes del Estado, en la represión de los movimientos sociales en la región. Vladimir Carrillo y Tom Kucharz realizan, desde el exilio, toda una denuncia de hechos recién ocurridos. Asimismo, Mauricio Archila, reconocido historiador social del país, desde un punto más analítico, se interesa por describir y explicar dicha incidencia en la década de 1990.

A partir de entonces, el "relevo" de las investigaciones sobre movimientos sociales es tomado por autores locales, signo del crecimiento de las universidades de la región en los estudios humanísticos y sociales. Las investigaciones de los últimos 10 años se han interesado mayoritariamente por estudiar épocas poco abordadas por anteriores trabajos: especialmente la segunda mitad del siglo XX, (si bien hay un estudio sobre los años 30 y 40). También se enfocan en objetos más específicos,

\footnotetext{
${ }^{20}$ José Yunis, y Carlos Hernández, Barrancabermeja. Nacimiento de la clase obrera. (Bogotá, Tres Culturas, 1986); Mauricio Archila, Aquí nadie es forastero: testimonios sobre la formación de una cultura radical (Barrancabermeja 1920-1950. Bogotá, CINEP, 1986. Serie Controversia): 133-134.

${ }^{21}$ Edward Palmer Thompson, La formación de la clase obrera en Inglaterra. (Barcelona, Crítica).
} 
tales como huelgas, coyunturas, municipios más pequeños y organizaciones sociales particulares.

De esta forma, Isaías Tristancho y Mario Cediel, sindicalistas, publicaron un interesante texto de historia del sindicalismo en Santander, para el cual recorrieron, durante dos años y medio, varios municipios del departamento, entre ellos Barrancabermeja y Puerto Wilches, recopilando unos siete mil documentos de las empresas, los sindicatos, el Ministerio de Protección Social y las Alcaldías, con los que reconstruyeron algunas de las historias, e hicieron un banco de ocho mil fotos. Junto a ellos estuvo Amado Guerrero, profesor de la escuela de historia de la UIS, quien le dio el rigor histórico al tema, así como la estructura literaria al libro. Esta obra se convierte en referencia, sobre todo por su trabajo documental y la utilización de fuentes orales. Por su parte, Jaime Barba Rincón, autor oriundo de Barrancabermeja y vinculado con la ciudad, publica unos años más tarde, una historia general del movimiento obrero en la primera mitad del siglo XX.

Andrés Caro Peralta y Renan Vega Cantor editaron sendos estudios sobre coyunturas específicas del movimiento obrero barranqueño, especialmente las sonoras huelgas de 1948 y 1977, que fueron hitos de auge y decadencia del movimiento obrero. Caro Peralta, en un artículo, estudia la huelga de 1948 llevada a cabo los trabajadores petroleros de la Unión Sindical Obrera (USO) contra la Tropical Oíl Company, evidenciando que fue una manifestación concreta de la lucha por la nacionalización del petróleo colombiano en contra del capital monopolista. Esta huelga llevó a la nacionalización del petróleo y la creación de Ecopetrol. Por su parte, Renán Vega, otro historiador reconocido de los movimientos sociales en Colombia, se ocupa de Barrancabermeja, para estudiar la Huelga de 1977 llevada a cabo por la USO y que fue reprimida. Ahonda en las causas de la misma, en las características organizativas y en las formas de acción que desplegaron los huelguistas para sostener la protesta en medio de la represión del Estado a través de las fuerzas armadas, destacando que allí operó de manera implacable la lógica de considerar el conflicto laboral como un asunto de orden público y no como una cuestión de tipo social. Esta misma coyuntura de 1977, y con parámetros similares es estudiada por el joven historiador Daniel Orlando Ramírez en su trabajo de grado.

De la decadencia del movimiento obrero en los años 70 se pasa a la crisis de los 90 y 2000, la cual es abordada por Daniel Rueda Otero en su respectivo trabajo de grado para titularse historiador. Busca comprender las causantes de que la USO no lograra detener las reformas impuestas en la industria de los hidrocarburos, entre ellas la reestructuración de Ecopetrol y la escisión de la Agencia Nacional de Hidrocarburos (ANH), que desde 2003 se encargó de diseñar la política petrolera del país. Entre estas causantes están las reformas administrativas que llevaron a la disminución del personal contratado de forma directa por la empresa, la implementación de un riguroso régimen disciplinario, las políticas de desincentivación de la afiliación sindical y la violencia antisindical. En síntesis, este estudio buscó comprender la forma en que el sindicato fue debilitado por todas estas medidas y situaciones. 
Hacia un balance de la historiografía regional santandereana (Colombia): los municipios...

En este mismo sentido Gill Lesley estudia cómo una forma extrema del neoliberalismo fragmentó quebró al movimiento social existente en Barrancabermeja, infundió miedo en la vida cotidiana y generó redes violentas de clientelismo que florecieron en la ausencia de derechos. Sostiene que el poder y la violencia descontrolados privaron a los barranqueños de la coherencia necesaria para cuidarse a sí mismos y para captar las conexiones entre el pasado, el presente, y el futuro que son necesarias "para hacer historia".

Pero el movimiento obrero no solo ha sido analizado en sus dinámicas de confrontación y represión. Emilce Garzón Peña, en su tesis de maestría dirigida por Mauricio Archila, se interesa por la relación entre el derecho y los movimientos obreros, específicamente cómo el derecho fue apropiado por las organizaciones obreras en Barranca y cómo se gestó un derecho laboral, presionado por dichas organizaciones.

Si bien el sindicalismo obrero ha sido el principal objeto de las investigaciones sobre los movimientos sociales, en los últimos años se ha generado un interés por ampliar el estudio a otro tipo de organizaciones, desde cívicas hasta religiosas. Jhoney Díaz, en un artículo describe y analiza las protestas cívicas en Santander y los intentos por conformar movimientos cívicos en el departamento entre los años de 1970 a 1984, donde el aspecto central de las reivindicaciones pasaba a ser lo territorial, señalando las enorme diferencias entre las dos principales ciudades del departamento: Bucaramanga, donde la participación de los sectores cívicos en este periodo fue casi inexistente y Barrancabermeja, donde el movimiento cívico era motivado y acompañado por el movimiento obrero, de mucha más larga tradición y experiencia. Asimismo, Ruth Zárate y César Moreno publican un artículo que se introduce en la Memoria Histórica de Barrancabermeja del último tercio del siglo XX, estudiando relaciones sociales, económicas, políticas y culturales que caracterizaron y circundaron las movilizaciones sociales en el puerto petrolero.

Por su parte, René Jaimes, en su trabajo de grado en historia, se interesa por una experiencia local, y estudia la organización social y política de San Vicente de Chucurí entre 1962 y 1970. Encuentra que un club deportivo y un periódico trascendieron su ámbito como organizaciones, al integrar, con la administración municipal, una serie de acciones en torno a la discusión y promoción de la cultural, la educación, el deporte, la salud y el sentido de identidad, al tiempo que criticaban la ineficiencia administrativa del estado. El trabajo llevado a cabo por dichas asociaciones contribuyó a la organización social, apareciendo nuevos liderazgos y actores sociales que obtuvieron reconocimiento social, ampliaron sus redes y vínculos sociales, llevándolas a transitar del campo cívico al campo político, convirtiéndose en la base del partido político ANAPO en la ciudad.

Al mismo municipio pertenece el Instituto Cristiano de Promoción Campesina - ICPROC- nacido en los años 80 por iniciativa de la Iglesia Católica y que en los años siguientes se convirtió en un importante centro de formación de líderes campesinos, gestores de movimientos sociales. Daniel Alfonso León y Leidy Marcela 
Parada estudian, en un documento que permanece inédito, su vida institucional y los programas desarrollados en medio de una violencia política social y dificultades materiales.

Dentro de los movimientos sociales de la región que, desde las últimas décadas del siglo XX han tenido creciente impacto, se encuentran los de tipo feminista, y quizá el más conocido es la Organización Femenina Popular, un grupo de mujeres de la ciudad de Barrancabermeja que surgió en 1972 y que aún se encuentra vigente. Diana Zuley Bernal en una regular y subjetiva tesis de maestría en historia, presenta una descripción del periodo 1998 - 2008 en la cual la OFP debió afrontar el reto de un paramilitarismo que hizo mayor presencia, consolidó su control y atacó a las organizaciones sociales. La OFP encontró la forma de resistir y no permitir su extinción, asumiendo como principios políticos la autonomía y la civilidad y como instrumentos de lucha el lenguaje y los símbolos para la defensa de los derechos humanos. En la misma línea, Diana Berna Angélica Badillo y Juan Ricaro Aparicio estudian en su tesis de maestría, la historia del movimiento "Ruta pacífica de las mujeres" enfatizando la región del Magdalena Medio. Se trata de un movimiento feminista que se ha opuesto a la guerra y resistido a ella, buscando alternativas. Ambos trabajos mencionados se caracterizan por una abierta y poca disimulada simpatía hacia su objeto de estudio y una posición bastante subjetiva.

Vemos así, cómo los enfoques investigativos sobre esta línea, que inician centrados casi exclusivamente en el movimiento obrero, han ido orientándose cada vez más hacia el estudio de otras organizaciones sociales, en el marco de escenarios locales, especialmente de grupos cívicos, feministas, religiosos y culturales.

\subsection{Política y estado}

Un grupo interesante de las investigaciones históricas halladas se dedican al estudio de temas políticos y de configuración y funcionamiento de las instituciones estatales en esta región, donde, paradójicamente el estado parece haber brillado por su debilidad. Seguramente esta es una razón que ha motivado a los investigadores a trabajar este tema. Dos son los momentos privilegiados: la época colonial y el siglo $\mathrm{XX}$, especialmente la segunda mitad. Dos son las poblaciones más relacionadas: Girón y Barrancabermeja.

Las estructuras y comportamiento político de los grupos de poder durante la época colonial es estudiadas desde el caso de Girón y su provincia. El interés principal es comprender el funcionamiento de las élites políticas y la configuración del modelo de segregación social y política, propio del sistema colonial. Quizá la principal investigación en este campo la hizo Amado Guerrero, en los años 90, a través de dos obras, una inédita y otra publicada. En ellas analiza las estructuras políticas de la élite gironesa en el siglo XVIII y el manejo de las finanzas públicas y en ello ver cómo las élites defendían sus intereses económicos a través de su participación en el Estado. 15 años después, Edgar Lizarazo, en su trabajo de grado en historia dirigido por René Álvarez, continúa el estudio de las élites locales y la configuración de su 
poder a través de análisis del "honor" y particularmente la manera como se defendió jurídicamente este valor social ante irrespetos y desacatos. A partir de ello se construye un modelo del significado que tuvo en esa época la defensa del "buen nombre". Da cuenta de que dicho proceso estuvo ligado a la necesidad de mantener y defender la jerarquización y la estratificación, a fines de la época colonial y comienzos de la era republicana. Concluye que la "justificación real que llevaba a la defensa del honor por las vías legales, se sustentaba en la prioridad de preservar a toda costa el orden social y mental que se traducía en privilegios exclusivos para quienes lograban demostrar la existencia y posesión del honor".

Para el siglo XIX no encontramos investigaciones que aborden la región específica o alguna de las poblaciones de la misma; aunque sí existen trabajos centrados en el análisis de las estructuras político-administrativas de la Provincia del Socorro, del Estado de Santander (1857-1886) y del Departamento de Santander (1886-1902), entre los cuales se destacan especialmente los libros y artículos de Armando Martínez Garnica, quien ha dedicado más de 20 años a la historia de la construcción del estado nacional colombiano, de las agendas de los gobiernos y de líderes políticos representativos. Sin embargo, aún no se ha indagado en el escenario subregional o local.

Respecto al siglo XX, las investigaciones sobre la configuración política subregional vuelven a aparecer, pero ahora centradas ya no tanto en las estructuras estatales, sino en el comportamiento del Estado ante los movimientos sociales, en el rol político jugado por estos y más recientemente, a la influencia de los grupos paramilitares en las estructuras políticas locales. En este subtema interesa el artículo de Gill Lesley, ya mencionado, que examina las relaciones entre neoliberalismo, paralimitarismo y política local. Otras investigaciones, estudian, también para el caso de Barrancabermeja, luchas de poder de los distintos sectores políticos locales en torno a la alcaldía de la ciudad en una época crucial para su historia y sus planes, proyectos y acciones administrativas. Vemos, entonces, que en el ámbito político los análisis sobre estructuras, administraciones, configuración y actores políticos tiene aún muchos vacíos, y apenas se ha trabajado de forma fragmentada los casos del Girón colonial y la Barrancabermeja de las últimas dos décadas.

\subsection{Religión}

Los temas religiosos se encuentran en penúltimo lugar en nuestras estadísticas sobre historiografía producida sobre la subregión del río Sogamoso. Apenas encontramos una investigación publicada sobre la época colonial, en torno al estudio de los imaginarios sobre la muerte en la provincia de Girón, por el profesor Luis Rubén Pérez. Para el siglo XIX hay un estudio biográfico publicado en 1955 sobre el obispo Evaristo Blanco, quien estuvo al frente de la diócesis del Socorro (y que incluía entonces buena parte de la ribera oriental del Río Magdalena santandereano). Respecto a los siglos XX y XXI existe afortunadamente una interesante historia general de la diócesis de Barrancabermeja, escrita por Jaime Barba Rincón, y que abarca desde sus antecedentes, hasta el presente. Aunque es descriptiva y gira en 
torno a la historia institucional, trata además otros aspectos, como la pastoral social, la construcción material de templos, la relación entre clero y movimientos sociales. Mucho más reciente es un artículo de William Plata y Helwar Figueroa sobre cómo la diócesis de Barrancabermeja organizó su pastoral social para resistir los embates del paramilitarismo y otros grupos armados en el periodo 1988-2005. Estos tres textos constituyen las únicas publicaciones en torno a la historia de la institucionalidad eclesiástica en la subregión que nos compete. Otras obras abordan la historia de ciertas organizaciones religiosas o de origen religioso locales importantes para la vida social y cultural de la zona: el colegio Santo Tomás de Zapatoca, que ha realizado desde los años 20 el siglo anterior una importante labor educativa en un radio que va más allá de dicha población y el Instituto Cristiano de Promoción Campesina - ICPROC, fundado en San Vicente y que ha desplegado desde los años 80 una importante labor en la promoción y formación en liderazgo de los campesinos de la región, en un contexto de luchas sociales y violencia armada. Sobre prácticas religiosas y evangelización solo se halló una investigación, inédita, sobre la religiosidad de un barrio de Barrancabermeja, a fines de los años 80 .

Sorprende y no la escasez de trabajos históricos sobre el hecho religioso. Por una parte, la Iglesia Católica, mayoritaria en la región, ha jugado un rol muy importante en el ámbito educativo, en cuestiones sanitarias, en la organización social y en la defensa de los derechos humanos - esto último especialmente en la segunda mitad del siglo XX- en una labor un tanto particular en relación con lo hecho por la misma institución en otras regiones del país; por otra parte, todo indica que el peso institucional de la Iglesia no ha sido tan poderoso e influyente como se cree en la mayor parte de la zona (la cual apenas comenzó a ser colonizada a finales del siglo XIX) y que su poder ha sido contestado por otras organizaciones religiosas (como las iglesias protestantes, evangélicas y pentecostales) sociales (sindicatos) y políticas (masonería). De manera que su labor e influencia ha sido un tanto invisible para la historiografía, que, hecha especialmente desde los centros universitarios, no le ha concedido mayor importancia. ${ }^{22}$

\subsection{Otros temas}

En esta miscelánea encontramos especialmente asuntos relacionados con geografía y medio ambiente, salud, educación y servicios públicos. Sobre lo primero, las investigaciones apenas abordan la geografía y el entorno como "escenario" de proyectos de colonización, fundación de pueblos y construcción de caminos. ${ }^{23}$ Es decir, no ha sido este un tema específico de trabajo; no al menos desde la historia, a pesar de la riqueza natural y el impacto que sobre ella ha tenido actividades como la explotación petrolera y la reciente construcción de la represa sobre el río Sogamoso. De manera que la historia ambiental de la zona está toda por hacer.

\footnotetext{
${ }^{22}$ William Elvis Plata, (ed.), El Hecho religioso. Historia en perspectiva Regional. (Bucaramanga, UIS, 2013): 7-24.

${ }^{23}$ Ver los apartados relacionados con colonización y comunicaciones.
} 
Hacia un balance de la historiografía regional santandereana (Colombia): los municipios...

Sobre lo segundo, sorprende que prácticamente permanece virgen, a pesar de ser siempre un tema de primer orden, máxime en una región caracterizada por sus problemáticas en materia de salubridad, calidad del agua, enfermedades tropicales, infecciones, etc. Solo hemos hallado una pequeña investigación de Carlos Caicedo en torno a la historia del suministro de agua en Barrancabermeja. Prácticamente podemos decir lo mismo sobre la cuestión educativa, otra materia de primer orden, que ha tenido algunas incursiones para otras subregiones del departamento y en el ámbito departamental, pero no para los municipios del área interesada.

\section{Conclusiones}

El estado del arte sobre las investigaciones de historia y memoria sobre la subregión del Río Sogamoso muestra, por una parte, un interés progresivo por parte de investigadores, ligados especialmente a las universidades públicas (UIS y Nacional especialmente). Dichas investigaciones se han centrado en temáticas relacionadas con poblamiento, colonización, apertura de caminos, empresarios, petróleo, movimientos sociales, dinámicas políticas y conflicto armado. Esto responde a las exigencias de una región compleja, poblada irregularmente, con grandes recursos naturales y energéticos, estratégica para las comunicaciones y la economía, pero olvidada por el Estado y por lo mismo, presa de los intereses de políticos corruptos, de grupos armados y delincuenciales. Por estas razones, las épocas más estudiadas cobijan los siglos XIX y XX y el municipio más estudiado es Barrancabermeja y la zona circundante. De manera que aún existen grandes vacíos sobre los mismos temas -especialmente de colonización y poblamiento- de otros municipios como Betulia, San Vicente, Puerto Wilches, Sabana de Torres, Lebrija, Zapatoca, y Los Santos, que inicialmente no han sido considerados importantes en esta "agenda".

Existe un interesante número de obras sobre temas económicos que abarcan la región del río Sogamoso, y que nos permiten comprender las lógicas de los procesos de colonización en la región a fines del siglo XIX y comienzos del XX y el despunte y desarrollo de la economía minera como principal sustento económico de la zona. Las investigaciones se concentran sobre todo en los siglos XIX y primera mitad del XX y faltan trabajos sobre la segunda mitad del siglo, para conocer cómo la economía abarcó otros sectores y cómo la ilegalidad y la violencia armada se intrincó con ella. Aunque se han estudiado algunos empresarios, aún se trata de aproximaciones.

Las investigaciones sobre vías y medios de comunicación manifiestan que, si bien desde temprano se buscó conectar la región con el mercado exterior a través del río Magdalena y la Costa Caribe, los proyectos sufrieron retrasos, quiebras, problemas de toda índole, tanto los caminos reales, como la vía fluvial. Además, los estudios evidencian que, aunque se buscó la conexión internacional, no se procuró la conexión interna, de manera que los municipios del área del Magdalena Medio se mantuvieron muy mal comunicados con los de la zona andina, aún con la capital departamental. Por lo demás nada se ha investigado sobre el asunto a partir de la segunda mitad del siglo XX. El tema parece concluir con el ferrocarril a Puerto Wilches y la era de los camiones y carreteras sigue sin estudiarse. 
El descubrimiento de petróleo generó olas migratorias de distintas partes del país, especialmente a Barrancabermeja, en calidad de obreros y trabajadores no cualificados que debieron organizarse para cambiar las duras condiciones de trabajo que ofrecían las empresas petroleras, especialmente la "Troco" (Tropical Oil Company). Todo ello generó una serie de movimientos sociales, forjándose así lo que algunos llaman una "cultura radical", que luego se vio confrontada con la Violencia de los años 50, la irrupción de las guerrillas y luego, la represión estatal y la invasión paramilitar. Esta historia supera el interés local, convirtiéndola en un "caso emblemático" tanto del movimiento social colombiano, como de las dinámicas del conflicto armado que ha azotado al país. Se entiende entonces por qué estas temáticas predominen en las investigaciones.

Ahora, pese a ello, es paradójico que los temas sobre memoria histórica del conflicto armado en la región son muy escasas; el esfuerzo realizado por instituciones como el Centro Nacional de Memoria Histórica en otras regiones del país no ha repercutido aquí. La tarea de hacer un ejercicio sistemático de reconstrucción de la memoria histórica del conflicto desde las víctimas sigue pendiente.

Tampoco se conoce mucho sobre la dinámica política, más allá de lo ligado al conflicto armado y los movimientos sociales. No sabemos mucho sobre la conformación y funcionamiento del Estado, sobre la cultura política, sobre las redes clientelistas, sobre los partidos políticos, etc.

Las cuestiones sobre salud, educación, religión, se encuentran muy poco exploradas. ¿Cómo explicar esto, especialmente cuando se trata de aspectos tan sensibles para la vida de las sociedades? Al parecer, la incidencia de lo político, lo relacionado con movimientos sociales, la colonización, los temas económicos la misma guerra y violencia armada experimentada en la zona ha monopolizado la óptica de las investigaciones y apenas ha habido algún interés por esos otros aspectos, que esperamos, en el marco de una sociedad posconflicto permitan ser visibilizados, interesados y analizados que permiten tener visiones más completas y globales sobre la historia y memoria de las comunidades de esta región.

Sorprende, finalmente el desinterés por la historia ambiental y la geografía histórica de una subregión tan rica en recursos y tan marcada por actividades de explotación de dichos recursos, como la explotación petrolera, la minería, la agroindustria y la construcción de una hidroeléctrica.

La región ha interesado por ser escenario de procesos que han incidido en el ámbito macrorregional y nacional: poblamiento, colonización, construcción de vías, ser germen de movimientos sociales, por existir tumbas indígenas allí, por ser escenario de violencia y conflicto armado. Pero no se ha estudiado en función de los intereses de sus comunidades, es decir, la región por sí misma, como objeto de estudio. Las comunidades de la zona no se han visto reflejadas en los estudios que se han hecho, que o bien son muy académicos y responden a comprensión de procesos globales, o no pasan de la anécdota y el dato (y donde los sujetos históricos son 
Hacia un balance de la historiografía regional santandereana (Colombia): los municipios...

las élites locales), sin decir mucho sobre los "para qué" y "por qué" de la historia que se narra. Las características de edición y difusión de dichos trabajos tampoco han permitido que las comunidades accedan al conocimiento de la historia que se ha investigado.

Resalta además la falta de trabajos de tipo microhistórico, que aborde la historia local desde sus propias lógicas y que responda a los intereses de la población que allí vive y en la cual ella sea protagonista. Así, se justifica la necesidad de elaborar estudios completos, integrales sobre la historia y memoria de los municipios de la región, abordando sus distintos componentes, respondiendo a las exigencias de una población que necesita con urgencia reconocerse, comprender, analizar y valorar su pasado, para vivir mejor su presente y planear su futuro.

\section{Bibliografía}

\section{Sociedad Y Cultura}

\subsection{Demografía histórica}

Rodrigo, Álvarez y Riaño de Rojas, Clemencia. "Demografía histórica e historia social de Girón, 1730-1800”. Tesis, Historia, Universidad Industrial de Santander, (2000): 191.

\subsection{Pueblos prehispánicos e indígenas}

Ardila Díaz, Isaías. El pueblo de los Guanes raíz gloriosa y fecunda de Santander. Bogotá: Sena, 1978.

Eljach, Alfonso. El Cacique Pipatón Barrancabermeja: Aserquerri, 1980.

Galvis Arenas, Gustavo y otros. El arte del tejido en el país de Guane. Bucaramanga: Banco de la República, Academia de Historia de Santander, 1993.

Martínez Garnica, Armando. El régimen del resguardo en Santander. Bucaramanga: Gobernación de Santander, 1993.

Morales Gómez, Jorge y Camargo, Gilberto. Investigaciones etnohistóricas y arqueológicas en el área Guane. Bogotá: Banco de la República - Fundación de investigaciones arqueológicas nacionales, 1984.

Moreno, Leonardo. "Arqueología del Nororiente colombiano. Los Teres: un sitio de asentamiento de las culturas prehispánicas Preguane y Guane". Anuario de Historia Regional y de las Fronteras 17. 2 (2012): 115-142. 
Moreno, Leonardo. "Los Teres: un asentamiento ordenador del territorio PreguaneGuane. Una aproximación al tema urbano". Anuario de Historia Regional y de las Fronteras 18. 2 (2013): 479-498.

Moreno, Leonardo. "Una aproximación a la sociología religiosa de la cultura prehispánica Guane: muerte y prácticas funerarias”. Anuario de Historia Regional y de Las Fronteras 17. 1 (2012): 13-27.

Moreno, Leonardo. Territorio y paisaje político en el Magdalena Medio en el siglo XVI Bucaramanga: Universidad Cooperativa de Colombia, 2000.

Navas, Alejandro y Angulo, Erika Marcela. Los guanes y el arte rupestre xerirense: la revelación de lo desconocido y el redimensionamiento de lo antes afirmado con la más completa muestra y análisis del arte rupestre mesetario realizado hasta el momento. Bucaramanga: SIC Editorial, Fundación El Libro Total, 2010.

Pérez, Roberto Lleras y Vargas, Arturo. "Palogordo: La prehistoria de Santander en los Andes orientales". Boletín del Museo del Oro 26. (1990): 64-129.

Pérez, Roberto Lleras. "Diferentes Oleadas de Poblamiento en la Prehistoria Tardía de los Andes Orientales”. Boletín del Museo del Oro 38-39. (1995): 10.

Reichell Dolmatoff Alicia y Martínez Garnica Armando. El mundo Guane: pioneros de la arqueología en Santander: Justus Wolfram Schottelius y Martín Carvajal. Bucaramanga: Gobernación de Santander, Universidad Industrial de Santander, 2005.

Schotellius, Justus. "Arqueología de la Mesa de los Santos". Boletín de arqueología 2.3 (1946): 213-225.

Velásquez, Rafael Antonio y Castillo, Víctor Julio. Territorio y poblamiento indígena en el Magdalena Medio: cacicazgos de los Yareguies, siglos XVI-XIX. Barrancabermeja: Alcaldía Municipal, 2001.

Velásquez, Rafael Antonio. Los yareguies. Resistencia y exterminio. Barrancabermeja: Corporación Memoria y Patrimonio, 2011.

\subsection{Esclavos y afrodescendientes}

Castaño, Yoer. "Esclavos libertos en la jurisdicción de Girón, 1682-1750" . Tesis, Maestría en Historia, Universidad Industrial de Santander, 2008.

Lamus, Doris. “Aquí no hay negros': develando la presencia de población afrodescendiente en Santander, Colombia”. Reflexión Política 16. 31 (2014): 114131. 
Hacia un balance de la historiografía regional santandereana (Colombia): los municipios...

Lamus, Doris. "Esclavos, libres y bogas en Santander, Colombia". Reflexión Política 16. 32 (2014): 114-131.

\subsection{Cultura campesina}

Asociación Campesina Comunitaria Venceremos. Venceremos: memoria de una lucha campesina: vereda Venceremos Zapatoca, Santander. (Bogotá: Ministerio de Cultura, 2014) 148.

Castillo, Fidel. Historia de la cultura campesina santandereana y su arraigo en el departamento de Santander. Bucaramanga: Gobernación de Santander, 2012.

\subsection{Familia, vida cotidiana, fiestas, alimentación y folclor}

Caicedo, Carlos. Agua: color, olor y sabor. Barrancabermeja: CINEP, 1993.

Gómez, Juan J. Memorias de la familia Acevedo Díaz de Zapatoca. Bucaramanga: SIC, 2002.

Gutiérrez de Pineda, Virginia. Honor, familia y sociedad en la estructura patriarcal el caso de Santander. Bogotá: Universidad Nacional, 1988.

Lizarazo, Edgar Fabián. “Atentados al honor: irrespetos y desacatos a la autoridad, San Juan de Girón 1781-1830”. Tesis, Historia, Universidad Industrial de Santander, 2009.

Sierra, Freddy Alexander. "Aguardiente de caña: consumo e intervención estatal en Santander (1923-1953)". Tesis, Maestría en Historia, Universidad Industrial de Santander, 2013.

Rico, Roger. Tahúres, chicherías y celebraciones monárquicas en el Santander colonial. Bucaramanga: SIC Editorial, 2014.

Zambrano, Juan Camilo. "Pleitos por limpieza de sangre en Girón y Vélez, 17801810". Tesis, Historia, Universidad Industrial de Santander, 2009.

\section{Colonizacion, poblamiento y vida urbana}

Angarita, Cesar y Gómez, Patricia. Enciclopedia de Santander: un pueblo que no conoce su historia no puede proyectar su futuro. Bucaramanga: SIC Editorial, 2006.

Aprile-Gniset, Jacques. Génesis de Barrancabermeja. Barrancabermeja: Instituto Universitario de La Paz, 1997.

Arcila, María Teresa. Un mundo que se mueve como el río. Historia regional del Magdalena Medio. Bogotá: Instituto Colombiano de Antropología, 1994. 
Ardila, Isaías. Zapatoca. Bogotá, Editorial Ariel, 1988.

Ardila, Reinaldo. San Vicente de Chucuri, 1878-1978: pujanza y prosperidad de Santander. Bucaramanga: Gráficas El Valle, 1978.

Arenas, Emilio. El viaje. Bogotá: Congreso de Colombia, 1997.

Arenas, Emilio. Siete leguas: Proceso histórico de poblamiento y posicionamiento urbano en Santander. Bucaramanga: Universidad Santo Tomás, 2008.

Arenas, Manuel Serrano San Juan de Girón: Ciudad eterna. Bucaramanga: Cámara de Comercio, 1973.

Báez, Enrique. Parroquias de Santander. Bogotá, inédita, 1950.

Delgado, Ricardo. “Anotaciones históricas sobre la colonización de Santander: siglo XIX”. Tesis, Historia, Universidad Nacional de Colombia, 1981.

Duque, Ivonne Marcela. "Compra - ventas de tierra rural y urbana, Girón 1886-1905” (Tesis, Historia, Universidad Industrial de Santander, 2009.

Duque, Ivonne Marcela. "Crecimiento urbano en la configuración del área periférica de San Juan de Girón, 1964-1985 (Santander-Colombia)”. Historia Crítica 60. (2016): 19.

Duque, Ivonne Marcela. "El crecimiento urbano de San Juan de Girón visto a partir del estudio de la configuración de su periferia 1964 - 1985". Tesis, Maestría en Historia, Universidad Industrial de Santander, 2016.

Flórez, Carlos y Castañeda, Luisa. Así se pobló la ciudad. Crecimiento urbano en Barrancabermeja. 1970-1990. Barrancabermeja: Alcaldía Municipal, 1997.

Galvis, Simón. Monografía de Barrancabermeja. Barrancabermeja: s.E., 1966.

Garnica Martínez, Manuel. "Guarapo, champaña y vino blanco: presencia alemana en Santander en el siglo XIX”. Boletín cultural y bibliográfico 29. 29 (1992): 20.

Gómez Valderrama, Pedro y otros. Zapatoca: una imagen de la provincia colombiana. Bogotá: Humberto Gómez Castillo, 1985.

Gutiérrez, Amado y Páez, Laritza. Poblamiento y conflictos territoriales en Santander. Bucaramanga: Universidad Industrial de Santander, 2005.

Gutiérrez, José Fulgencio. Santander y sus municipios. Bucaramanga: Imprenta del Departamento, 1940. 
Hacia un balance de la historiografia regional santandereana (Colombia): los municipios...

Guzmán, Ángela. Poblamiento y urbanismo colonial en Santander. Estudio de 10 pueblos de la región central. Bogotá: Universidad Nacional, 1987.

Hernández Camacho, Carlos Nicolás. Mesa de los Santos: memorias del paraíso. Bucaramanga: Fundemesa, 2003.

Leal, Carmen Rosa y otros. "Monografía del municipio de Los Santos”. Tesis, Historia, Universidad Industrial de Santander, 1979.

León, Daniel Alfonso. "Camino a Barrancabermeja: antecedentes del proceso de colonización en San Vicente de Chucurí, 1864-1900”. Anuario de Historia Regional y de las Fronteras 17. 2 (2012): 25.

León, Daniel Alfonso. "Proceso urbano en zona de frontera: experiencia de San Vicente de Chucurí entre 1870-1905". Tesis, Historia, Universidad Industrial de Santander, 2008.

León, Daniel Alfonso. "San Vicente de Chucurí: gobierno local y proceso de colonización 1886-1925". Tesis, Maestría en Historia, Universidad Industrial de Santander, 2013.

Martín Peré, Elisa María. "El derecho a la tierra en Santander: conflictos de tierras, justicia agraria y parcelaciones en el siglo XX". Tesis, Maestría en Historia, Universidad Industrial de Santander, 2016.

Martínez Carreño, Aída (ed.). Pueblos de Santander: procesos de desarrollo urbano. Bucaramanga: Terpel, 1996.

Martínez, Armando y Gutiérrez Ramos, Jairo. Historia de la subregionalización de los Santanderes. Bucaramanga: UIS, 1994.

Martínez, Armando y Gutiérrez, Amado. La provincia de Soto: orígenes de sus poblamientos urbanos. Bucaramanga: Ediciones UIS, 1996.

Martínez, Armando y Rueda Cardozo, Juan Alberto. La provincia de Mares. Orígenes de sus poblamientos urbanos. Bucaramanga: Ediciones UIS, 1996.

Méndez, María Oliva y otros. "Petróleo y Barrancabermeja". Tesis, Historia, Universidad Industrial de Santander, 1979.

Murillo Posada, Amparo. Historia de localidades en la región del Magdalena medio. Medellín: Plan Nacional de Rehabilitación - Colcultura - Universidad de Antioquia, 1991.

Nuñez, Rafael. Reseña Histórica de Barrancabermeja. Bogotá: Ediciones Nueva Colombia, 1987. 
Otero Prada, Diego Fernando. Historia de la Fundación de Barrancabermeja y el papel del petróleo. Bucaramanga: Corporación Universitaria de Ciencia y Desarrollo, 2015.

Pinzón, Gustavo Isaac. Historia de la Formación de Santander, sus Provincias y Municipios. Bucaramanga: SIC Editorial, 2007.

Restrepo, Blanca. Reminiscencias de San Vicente de Chucurí. Bogotá: Editorial Oveja Negra, Quintero Editores, 2007.

Rodríguez Plata, Horacio. La inmigración alemana al Estado Soberano de Santander en el siglo XIX repercusiones socio-económicas de un proceso de trasculturación (Bogotá: Editorial Kelly, 1968.

Rojas, José Manuel. Ciudades de Santander. Bogotá: ABC, 1939.

Rosas, Hermenegildo y otros. "Monografía del municipio de San Vicente de Chucurí". Tesis, Historia, Universidad Industrial de Santander, 1979.

Rueda, Mario Enciso. Memoria fotográfica y personajes de San Vicente de Chucurí. San Vicente de Chucurí: Municipio de San Vicente de Chucurí, 2015.

Serrano Besil, Javier Eduardo. "Industria y ciudad. Crecimiento urbano de Barrancabermeja, 1926 - 1936”. Anuario de Historia Regional y de las Fronteras 18. 1 (2013): 17.

Serrano Besil, Javier Eduardo. Crecimiento urbano de Barrancabermeja. 1926-1936. Bucaramanga: UIS, 2013.

Torres, Jaime. “Monografía de Girón”. Tesis, Universidad Industrial de Santander, 1979.

Tristancho, Gerardo y Ballesteros, Néstor. Emporio de la abundancia: San Vicente de Chucurí. Bucaramanga: Impresores colombianos, 1978.

Valvuena, Martiniano Memorias de Barrancabermeja. Bucaramanga: Editorial El Frente, 1947.

Vargas Velásquez, Alejo. Magdalena Medio Santandereano: colonización y conflicto armado. Bogotá: CINEP, 1992.

Villamizar, Evelia y Álvarez Salazar, Paula. "Origen y evolución del Municipio de Barrancabermeja”. Tesis, Historia, Universidad Industrial de Santander, 1979. 
Hacia un balance de la historiografia regional santandereana (Colombia): los municipios...

\section{Guerra, conflicto armado y violencia}

Alonso, Manuel Alberto. "Conflicto armado y configuración regional: el caso del Magdalena Medio", Revista de Estudios Políticos 2. (1992): 87-111

Alonso, Manuel Alberto. Conflicto armado y configuración regional: el caso del Magdalena Medio. Medellín: Universidad de Antioquia, 1997.

Becerra, Silvia Juliana. "Neoliberalismo y paramilitarismo en Barrancabermeja, 19902005 ”. Tesis, Maestría en Historia, Universidad Nacional de Colombia, 2008.

Camelo, José Nelson. Violencia y criminalidad en Santander. 1985-1998. Análisis de sus costos económicos. Bucaramanga: UIS - SIC Editorial, 2002.

Cinep. Barrancabermeja, la otra versión. Paramilitarismo, control social y desaparición forzada. Bogotá: CINEP- CREDHOS Colección Revista Noche y Niebla No. 3, 200.

Comisión Intercongregacional de Justicia y Paz. El proyecto paramilitar en la región de Chucurí (Informe inédito). Bogotá: Cinep Justicia y Paz, 1992.

Correa, Viviana. Reseña histórica del surgimiento del conflicto armado en el departamento de Santander. Bucaramanga: Uniciencia, 2014.

CRDH. Magdalena medio. Hoy como ayer persistiendo por la vida. Informe sobre redes de inteligencia y exterminio en Barrancabermeja. Santafé de Bogotá: Corporación Regional para los Derechos Humanos, Corporación Colectivo de Abogados “José Alvear Restrepo”, 1999.

Gill, Lesley. "Disorder and Everyday Life in Barrancabermeja" Colombia Internacional 73. (2011).

Hernández, Milton. Rojo y negro. Historia del ELN. Buenos Aires: Exteberría, 2005.

Jaimes, Diego Andrés. "La Guerra civil de 1876-1877 al interior del Estado Soberano de Santander”. Tesis, Historia, Universidad Industrial de Santander, 2016.

Jiménez Meneses, Orián y Gonzáles Vélez, Estefanía. Las guerras del Magdalena Medio Medellín: Intermedio Editores, 2008.

Meléndez Sánchez, Jorge. Y aquí cayó Camilo. Bogotá: El Búho, 1996.

Merchán, Robert Jaimes. "Homicidios perpetrados por grupos paramilitares que operaron en Santander durante 1990 - 2005". Tesis, Historia, Universidad Industrial de Santander, 2010. 
Molano, Alfredo. En medio del Magdalena Medio. Bogotá: Cinep, Cordaid, Programa de Desarrollo y Paz del Magdalena Medio, 2009.

Obregón, Martha Arenas. Cerrando fronteras: historias contadas del Magdalena Medio. Bucaramanga: Programa de Desarrollo y Paz del Magdalena Medio, Colección Redes No. 2, 1999.

Ortiz, Carolina Becerra. "La guerra civil de 1859-1862 en el estado de Santander durante la Confederación Granadina". Tesis, Historia, Universidad Industrial de Santander, 2013.

Plata, William Elvis. "Iglesia, resistencia pacífica y no violencia. La Diócesis de Barrancabermeja, Colombia (1988-2005)", Anuario de historia regional y de las fronteras 22. 1(2017): 32 .

Prada, Diego Silva. Asociaciones campesinas en resistencia civil: construcción de paz y desarrollo en el Magdalena Medio. Bogotá: Corporación Universitaria Minuto de Dios, 2011.

Romero, Amanda. Magdalena Medio. Luchas sociales y violaciones a los derechos humanos, 1980-1992. Santafé de Bogotá: Corporación AVRE, 1994.

Rueda, Eduardo y otros. La guerra de los Mil Días en las letras santandereana Bucaramanga: Alcaldía de Bucaramanga: Instituto Municipal de Cultura y Turismo, 2000.

Vargas, Alejo. "Tres momentos de la violencia política en San Vicente de Chucurí: de los bolcheviques del año 29 a la fundación del ELN". Análisis Político 8. (1989): 16.

Villabona, Zaida Acosta. "Narrativas de vida en torno a un hecho violento: la masacre del 16 de mayo de 1998 en Barrancabermeja”. Tesis, Historia, Universidad Industrial de Santander, 2016.

\section{Economía}

Becerra, Silvia Juliana. "Paramilitarismo y neoliberalismo en Barrancabermeja, El caso de la privatización de Ecopetrol 1980-2000". Ciencia Política 4.7 (2009): 125-149.

Bohórquez Barrera, Jesús. "El mercado de tierras: la historia económico-cultural y el establecimiento de los tempus económicos en el mundo rural neogranadino. La provincia de Girón (1680-1770)"'. Fronteras de la Historia 12. (2007): 41.

Bohórquez Barrera, Jesús. "Tierras y vecinos en la provincia San Juan Girón 16801770”. Tesis, Historia, Universidad Industrial de Santander, 2006. 
Hacia un balance de la historiografía regional santandereana (Colombia): los municipios...

Carreño, Clara Inés y Maldonado, Cintya. “Espíritu visionario? Geo von Lengerke: proyectos comerciales y de caminos en la segunda mitad del siglo XIX". Anuario colombiano de historia social y de la cultura 23. 2 (2009): 17-40.

Castañeda, Luisa y Villamizar, Nancy. "Producción de café en Bucaramanga, Lebrija y Matanza 1880-1912”. Tesis, Historia, Universidad Industrial de Santander, 1997.

Cuadros Sánchez, Miguel Darío. "Santander en declive: el fracaso de Bartolomé Rugeles con sus inversiones en torno al Ferrocarril de Puerto Wilches 1903-1916". Anuario de historia regional y de las fronteras 16. (2011): 151-173.

Duarte, Alexander y Contreras, Raúl "Dinámicas del uso del suelo y el conflicto armado en los municipios de Barrancabermeja, Sabana de Torres y Puerto Wilches de 1985-2000” (Tesis, Economía, Universidad Industrial de Santander, 2002.

Guerrero, Amado Antonio. "Finanzas y Administración del cabildo de la ciudad de San Juan de Girón”, Historia Crítica 14. (1997): 18.

Johnson, David Church. Santander siglo XIX: Cambios socioeconómicos. Bogotá: Carlos Valencia Editores, 1984.

Oliva Méndez, María y Ramírez, Rosa Celina. “Petróleo y Barrancabermeja”. Tesis, Historia, Universidad Industrial de Santander, 1979.

Ortíz, Álvaro Pablo Geo. von Lengerke: constructor de caminos. Bucaramanga: Ediciones UIS, 2008.

Oswaldo Ortiz, Lenin. "Precios, productores y especuladores: el consumo de arroz y carne bovina en Santander: 1940-1950". Tesis, Historia, Universidad Industrial de Santander, 2012.

Palacio, Gabriel. "La circulación y el consumo en las cuencas de los ríos Sogamoso y Lebrija: comerciantes y consumidores en el siglo XVIII". Historia Crítica 35. (2008): 176-200.

Peralta, Edgar Andrés. “"El petróleo es de Colombia y para los colombianos'. la huelga de 1948 en Barrancabermeja y la reversión de la Concesión de Mares". Anuario de Historia Regional y de las Fronteras 18. 2 (2013): 383-407.

Pérez, Diana García. “Aspectos cuantitativos y cualitativos de la compraventa de tierras urbanas y rurales en Lebrija. 1950-1970”. Tesis, Historia y Archivística, Universidad Industrial de Santander, 2015.

Raymond, Pierre. El algodón y los tejidos en Santander: origen, decadencia y renacer de una tradición textil. Bogotá: ECOE Ediciones, 2013. 
Romero, Wilfred. "Finanzas en el estado soberano de Santander 1857-1886". Tesis, Maestría en Historia, Universidad Industrial de Santander, 2014.

Santiago, Miguel Ángel. Crónica de la concesión De Mares: apuntes sobre los principales acontecimientos que antecedieron a la creación de la Empresa Colombiana de Petróleos. Bogotá: Editorial Presencia, 1986.

Sierra, Freddy. "Aguardiente de caña: consumo e intervención estatal en Santander (1923-1953)". Tesis, Maestría en Historia, Universidad Industrial de Santander, 2013.

Tarazona, Clara Inés. “Construir caminos para conducir cargas y especular con tierras: los caminos de Lebrija y Sogamoso en el departamento de Soto, 1865-1885". Tesis, Historia, Universidad Industrial de Santander, 2007.

Villamizar Mendoza, Esperanza. "La adjudicación de baldíos en el estado soberano de Santander: 1857 - 1886”. Tesis, Maestría en Historia, Universidad Industrial de Santander, 2000.

\section{Movimientos sociales}

Archila, Mauricio Conflictos, poderes e identidades en el Magdalena Medio: 19902001. Bogotá, CINEP - Colciencias, 2006.

Arcila, María Teresa Un mundo que se mueve como el río. Historia regional del Magdalena Medio. Santafé de Bogotá: Instituto Colombiano de Antropología, 1994.

Badillo, Angélica y Aparicio, Juan Fernando. "Una década de movilizaciones: Ruta Pacífica de las Mujeres Santander 2001-2011. Prácticas y manifestaciones en el conflicto armado colombiano”. Tesis, Maestría en Estudios Culturales, Universidad de los Andes, 2015.

Bernal, Diana Zuley. "Historia de la Organización Femenina Popular en Barrancabermeja: 1998-2008". Tesis, Maestría en Historia, Universidad Nacional de Colombia, 2014.

Cantor, Renán Vega. "Conflicto petrolero en Barrancabermeja en 1977: 'no fue una huelga, fue una guerra"'. Anuario Colombiano de Historia Social y de la Cultura 35. (2008): 247-276.

Carrillo, Vladimir y Kucharz, Tom. Colombia: terrorismo de estado. Testimonios de la guerra sucia contra los movimientos populares (Barcelona: Icaria Editorial, 2006. 
Hacia un balance de la historiografía regional santandereana (Colombia): los municipios...

Díaz, Jhoney. "Ciudad y protesta: Las luchas cívicas en Santander 1970-1984". Anuario de Historia Regional y de las Fronteras 18. 1 (2013): 161-191.

Jaimes, René Parra. "De la asociación cívica a la organización política en San Vicente de Chucurí (1962-1970)”. Tesis, Historia, Universidad Industrial de Santander, 2011.

León, Daniel Alfonso y Parada, Leidy Marcela. Reseña Histórica del Instituto Cristiano de Promoción Campesina -ICPROC "Floresmiro López Jiménez" 1982-2007 (Inédito) (San Vicente de Chucurí: ICPROC, 2007) http://icproc.org. co/administrador/repositorio/Rese $\% \mathrm{C} 3 \% \mathrm{~B} 1 \mathrm{a} \_$Historica_icproc.pdf

Lesley, Gill."Disorder and Everyday Life in Barrancabermeja". Colombia Internacional 73. (2011): 49-70.

Peña, Emilce Garzón. "Historia de los imaginarios y realidades del derecho: usos y prácticas jurídicas de los trabajadores petroleros 1935-1948”. Tesis, Maestría en Historia, Universidad Nacional de Colombia, 2009.

Ramírez, Daniel Orlando. "Barrancabermeja, una ciudad rebelde: la huelga de 1977 y la Cultura obrera”. Tesis, Historia, Universidad Industrial de Santander, 2016.

Rincón, Jaime Barba. Las luchas obreras en Barrancabermeja y la Tropical Oil Company. Barrancabermeja: Alcaldía de Barrancabermeja, 2014.

Rodríguez, Sonia Mercedes. "Barrancabermeja, manifestaciones culturales radicales: 1945-1990”. Tesis, Antropología, Universidad Nacional de Colombia, 1992.

Rueda Otero, Daniel Alexander. "Solos no pudimos". La pérdida de incidencia en los repertorios de acción social colectiva de la Unión Sindical Obrera (USO). Barrancabermeja, 1998 - 2003". Tesis, Historia, Universidad Industrial de Santander, 2015.

Tristancho, Isaías y Cediel, Mario. Historia oral del sindicalismo en Santander. Bucaramanga: UIS, Financiera Comultrasan, 2005.

Velásquez, Alejo. Magdalena Medio Santandereano: colonización y conflicto armado. Bogotá: CINEP, 1992.

Zárate, Ruth y Moreno, César. "De las movilizaciones sociales a las acciones colectivas por la paz, caso Barrancabermeja. 1970 - 2000". Prospectiva. Revista de Trabajo Social e Intervención Social 12. (2007) 251-272. 


\section{Vias de comunicación}

Arenas, Emilio. Siete leguas: Proceso histórico de poblamiento y posicionamiento urbano en Santander. Bucaramanga: Universidad Santo Tomás, 2008.

Carreño, Augusto Olarte. La construcción del ferrocarril de Puerto Wilches a Bucaramanga, 1870 a 1941: síntesis de una obra discontinua y costosa. Bucaramanga: SIC Editorial, 2006.

Centeno, David Felipe. "Economía, política y ferrocarril en Santander: la construcción del ferrocarril de Soto al Magdalena, 1870-1885". Tesis, Historia, Universidad Industrial de Santander, 2010.

Correa, Juan Santiago. Café y ferrocarriles en Colombia: los trenes santandereanos (1869 - 1990). Bogotá: Colegio de Estudios Superiores de Administración CESA, 2012.

León, Daniel. "Camino a Barrancabermeja: antecedentes del proceso de colonización en San Vicente de Chucurí, 1864-1900”. Anuario de Historia Regional y de las Fronteras 17. 2 (2012): 25.

Torres, Leidy Jerez. "El proyecto del Ferrocarril de Santander, 1870-1905”. Tesis, Historia, Universidad Industrial de Santander, 2010.

Niño, Miguel y Bayona, Judith. Del camino de Paturia al Ferrocarril de Santander. Bucaramanga: UIS, CER, 2002.

Ortega, Alfredo. "Historia del ferrocarril de Puerto Wilches", Anales de ingeniería 22. (2006): 77-84.

Rojas, Zandalio Durán. Generalidades de Puerto Wilches, Santander y otros datos. Bucaramanga: Uniciencia, 2006.

Sergio Rangel, A paso de Yuma (Bucaramanga: SIC Editorial - El Libro Total, 2004) 398.

\section{Política y estado}

Estupiñán Aguilar, Ernesto. "Historia de las alcaldías populares en Barrancabermeja: (1988-2011”. Tesis, Historia, Universidad Industrial de Santander, 2013.

Garnica Martínez, Armando. “"La experiencia histórica de las divisiones políticoadministrativas en Santander. Legados y retos futuros' La Incidencia de las Instituciones de Santander en la Consolidación de la República de Colombia”. Bogotá: Procuraduría General de la Nación, Instituto de Estudios del Ministerio Público, 2015. 
Hacia un balance de la historiografía regional santandereana (Colombia): los municipios...

Garnica, Armando Martínez. "'El camino hacia la constitución en la provincia del Socorro'En: Las Constituciones de la Primera República, Memorias del Coloquio Conmemorativo del Bicentenario de la constitución de la República de Tunja de 1811”. Bogotá: Ediciones Academia Colombiana de Jurisprudencia, 2012.

Guerrero, Amado. "Finanzas y Administración del cabildo de la ciudad de San Juan de Girón”. Historia Crítica 14. (1997).

Guerrero, Amado. La política local en la sociedad colonial: Girón, siglo XVIII (Inédito). Bucaramanga: UIS, 1993.

Lizarazo Pedraza, Edgar Fabián. "Atentados al honor: irrespetos y desacatos a la autoridad, San Juan de Girón 1781-1830”. Tesis, Historia, Universidad Industrial de Santander, 2009).

Martínez Garnica, Armando. “'Leonardo Canal: un santandereano en la escena politica nacional”, La Incidencia de las Instituciones de Santander en la Consolidación de la República De Colombia’. Bogotá: Procuraduría General de la Nación, Instituto de Estudios del Ministerio Público, 2015.

Martínez Garnica, Armando. "La independencia en las provincias del Socorro y Pamplona", Estudio. Órgano de la Academia de Historia de Santander 333. 1 (2005) 158-164.

Martínez Garnica, Armando. Una familia Santos de Santander y de Colombia. Bucaramanga: Sic Editorial, 2013.

Núñez, Jorge. Crónicas de lucha por el poder local: testimonio de los hechos más sobresalientes ocurridos en Barrancabermeja 1985-1992. Barrancabermeja: Alcaldía Municipal (2 ed.), 1997.

Pacheco, Raúl. El León del Norte: el General Solón Wilches y el constitucionalismo radical Bucaramanga: SIC, 2002.

Romero, Wilfred "Finanzas en el estado soberano de Santander 1857-1886". Tesis, Maestría en Historia, Universidad Industrial de Santander, 2014.

\section{Religión e imaginarios}

Benítez Valderrama, Ernesto. Monseñor Evaristo Blanco: esquicio biográfico. Bucaramanga: Academia de Santander, 1955.

Galezo, Yadira. "Evangelización de la religiosidad popular del barrio Yarima en Barrancabermeja”. Tesis, Licenciatura en Filosofía y Ciencias Religiosas, Universidad Santo Tomás, 1989. 
León, Daniel Alfonso y Parada, Leidy Marcela. Reseña Histórica del Instituto Cristiano de Promoción Campesina -ICPROC "Floresmiro López Jiménez" 1982-2007 (Inédito) (San Vicente de Chucurí: ICPROC, 2007) http://icproc.org. co/administrador/repositorio/Rese $\% \mathrm{C} 3 \% \mathrm{~B} 1 \mathrm{a} \_$Historica_icproc.pdf

Pérez Pinzón, Luis Rubén. "Pensar la muerte: miedos e imaginario en la provincia de Girón: siglo XVIII”. Tesis, Historia, Universidad Industrial de Santander, 2000.

Pérez, Luis Rubén. "Pensar la muerte: miedos e imaginarios en la provincia de Girón: siglo XVIII” William E. Plata (ed.) El hecho religioso. Historia en perspectiva regional. Bucaramanga: UIS, 2013.

Plata, William Elvis y Figueroa, Helwar. "Iglesia, resistencia pacífica y no violencia. La diócesis de Barrancabermeja, Colombia (1988-2005)". Anuario de historia regional y de las fronteras 22.1 (2017) 32.

Rincón, Jaime Barba. Barrancabermeja: la Diócesis en memoria viva. Bogotá: Diócesis de Barrancabermeja, 2012.

Santo Tomás, Colegio Salesiano. Un pueblo, un colegio: 28 años de labor educativa salesiana en Zapatoca (1945-1973) (Zapatoca: Colegio 